\title{
La forma de la expansión urbana en una ciudad media del interior de la pampa bonaerense desde una perspectiva histórica urbano- ambiental (1779-2021)
}

\author{
The shape of urban expansion in a middle city in the interior of the pampa \\ bonaerense from an urban-environmental historical perspective (1779-2021) \\ Mariana Giusti \\ mariana.giusti@fadu.uba.ar @ 0000-0003-3016-8261 \\ Facultad de Arquitectura, Diseño y Urbanismo. Universidad de Buenos Aires (FADU-UBA). \\ Pabellón 3, Int. Güiraldes 2160. 1428 Ciudad Autónoma de Buenos Aires, Argentina.
}

\section{María Eugenia Goicoechea}

mariaeugenia.goicoechea@fadu.uba.ar (1) 0000-0002-8455-6772

Instituto de Estudios Sociales en Contexto de Desigualdades. Universidad Nacional de José C. Paz, CONICET.

Facultad de Arquitectura, Diseño y Urbanismo. Universidad de Buenos Aires (FADU-UBA).

Leandro N. Alem 4731, José C. Paz. 1665 Prov. Buenos Aires, Argentina.

\section{INFO ARTÍCULO}

Recibido: 02-06-2021

Revisado: 29-06-2021

Aceptado: 30-06-2021

\section{PALABRAS CLAVE}

Ciudades medias

Historia urbano-ambiental

Expansión urbana

Provincia de Buenos Aires

Chascomús

\begin{abstract}
RESUMEN
El presente artículo tiene por objetivo analizar las formas y tendencias que adoptó la expansión de la matriz edificada de una ciudad intermedia localizada en el interior de la región pampeana bonaerense (Chascomús, Provincia de Buenos Aires, Argentina). El estudio abarca el período 1779-2021 y se centra en la tríada historia, territorio y norma. Con un diseño metodológico que recupera y sistematiza una gran base empírica, se integran en el análisis: el efecto de las relaciones históricas, económicas y sociales; las características territoriales y ambientales; y la influencia de las normativas en las formas que adoptó la expansión urbana. El trabajo, además de ser ilustrativo de un contexto general de crisis del modelo de desarrollo geográfico basado en la primacía urbana y del cuestionamiento al afianzamiento de estructuras macrocefálicas, aporta al conocimiento de las dificultades que se presentan en este tipo de ciudades, recorriendo su conformación físico-espacial, sus limitaciones, amenazas y potencialidades.
\end{abstract}

\section{KEYWORDS}

Intermediary cities

Urban environmental history

Urban sprawl

Buenos Aires province

Chascomús

\begin{abstract}
The objective of this article is to analyze the forms and trends adopted by the expansion of the built matrix of an intermediate city located in the interior of the Buenos Aires Pampean region (Chascomús, Buenos Aires Province, Argentina). The study covers the period 1779-2021 and focuses on the triad of history, territory and norm. With a methodological design that recovers and systematizes a great empirical base, the following aspects are integrated into the analysis: the effect of historical, economic and social relationships; territorial and environmental characteristics; and the influence of regulations on the forms adopted by urban expansion. The work, in addition to being illustrative of a general context of crisis of the geographic development model based on urban primacy and the questioning of the consolidation of macrocephalic structures, contributes to the knowledge of the difficulties that arise in this type of cities, covering their physical-spatial conformation, its limitations, threats and potentialities.
\end{abstract}




\section{INTRODUCCIÓN}

En los últimos años, el campo disciplinar del ordenamiento y la planificación urbana en Argentina se ha propuesto recuperar los cuestionamientos clásicos sobre la primacía urbana y la macrocefalia característica de la matriz de desarrollo urbano latinoamericana, que concentra más del 50\% de la población en unos pocos centros urbanos. Frente al colapso socio-habitacional de las grandes áreas metropolitanas (agudizado recientemente por la pandemia de COVID-19) y las iniciativas públicas recientes de descentralización (Schweitzer, 2020), los pueblos y ciudades de menor escala resultan protagonistas en la transición hacia un desarrollo territorial más equitativo.

En el marco de estas reflexiones, el presente artículo parte de reconocer el contexto general de crisis ambiental y ecológica, y los cambios en las tendencias de poblamiento y procura centrar la mirada en los pueblos y ciudades menores, entendiendo el desafío que su estudio representa para avanzar hacia una mejora en el equilibrio del territorio nacional y la conformación de redes de ciudades sostenibles. Entonces nos preguntamos: ¿Bajo qué patrones y modelos han venido creciendo este tipo de ciudades?, ¿Con qué resultados en términos ambientales y sociales?, ¿Están preparados para recibir nuevas poblaciones? En el actual contexto de crisis ecológico-ambiental y económico-social, ¿han desarrollado instrumentos alineados con los paradigmas de la sostenibilidad y la mitigación del cambio climático?

La agenda latinoamericana de estudios urbano-territoriales, pese a la importancia estratégica de los entornos urbanos de menor escala y a las discusiones en materia de sostenibilidad, se ha concentrado en los centros mayores, especialmente en contextos metropolitanos. Particularmente, los trabajos sobre el interior bonaerense y las ciudades de escala media y pequeña han referido mayormente a abordajes históricos sobre la fundación de pueblos y ciudades en el periodo comprendido entre el SXIX e inicios del SXX (Levene, 1941; Razori, 1945; Cabodi, 1950; Morosi et al., 1991; De Paula, 2000, 2004; Aliata, 2006, 2010, 2010b; Politis, 2012; Pesoa Marcilla, 2012, 2016 y Vitalone, 2013). Otros antecedentes han analizado los elementos comunes en las estructuras urbanas de las ciudades pampeanas y han esbozado algunas problemáticas vinculadas con los procesos de expansión registrados hasta la década del setenta (Randle, 1977). Asimismo, se identifican otros trabajos interesados en el rol de las ciudades intermedias del interior bonaerense para una posible reestructuración territorial (Randle et al., 1992; Sassone, 1998).

Sin embargo, pocos trabajos han recogido el impacto de las políticas neoliberales en ciudades de esta escala, o la influencia de los modelos de explotación territorial ejercidos a partir de la década del noventa. Tampoco se observan estudios que analicen la extensa línea temporal comprendida entre los inicios de la urbanización y la etapa actual como un todo integral, o que incluyan, con relevancia teórica, al ambiente y al paisaje cultural en la historia y las formas de expansión de este tipo de urbes'

Tomando en cuenta los antecedentes señalados y sus vacancias, el presente trabajo muestra los resultados de un primer abordaje y sistematización de los procesos de transformación que se dieron en una ciudad de baja densidad del interior bonaerense a partir del estudio de caso de la ciudad de Chascomús (Provincia de Buenos Aires, Argentina). El objetivo general es caracterizar la forma urbana de la expansión a partir de la interrelación que se establece en la tríada: historia, territorio y norma. Es decir, analizar los efectos de las relaciones históricas, económicas y sociales; las características territoriales y ambientales; y las normativas, en las formas que adoptó la expansión urbana a lo largo de su historia hasta la actualidad (1779-2021). Como objetivos específicos se propone: 1 ) identificar diversas tendencias que a lo largo del tiempo dieron forma al crecimiento de la ciudad de Chascomús en consonancia con las dinámicas urbanas preponderantes, incluyendo perfiles productivos, orientaciones de la planificación urbana e instrumentos normativos e impacto sobre los ecosistemas naturales; 2) formular una reflexión crítica acerca de la forma en la cual se ha pensado y gestionado el crecimiento de las ciudades de escala media desde la política urbana tomando el caso de Chascomús.

Entonces, el diseño metodológico recupera y sistematiza fuentes primarias y secundarias a partir de las cuales se reconocen tres tendencias históricas del crecimiento chascomunense, según un tipo de visión y

1. Una profundización a esta dimensión del estudio puede encontrarse en Giusti et al., 2020 y Giusti, 2021 a partir del caso Chascomús. 
explotación territorial predominante: completamiento y compactación (1776-1945); ensanche y dispersión de la traza (1946-1989); y extrema dispersión residencial y densificación (1990-2021). Al interior de dichas tendencias, se emplean documentos históricos, planos y vuelos y se avanza en el mapeo y análisis de la matriz edificada. Con ello, se identifica cómo se combinaron en el tiempo y el espacio las fases parcelación, urbanización y edificación (Sola Morales, 1997), evidenciando la coexistencia de una diversidad de tipologías de tejidos y densidades en el paisaje urbano.

Esta mirada, que se propone a la vez sincrónica y diacrónica, no sólo aporta a la sistematización de un objeto de estudio poco explorado; sino que también ofrece un insumo para el diseño de políticas públicas a partir del conocimiento de la conformación físico-espacial del centro urbano, sus limitaciones, amenazas y potencialidades. En especial, cuando este tipo de ciudades continuará absorbiendo la expansión de sus matrices urbanas.

A continuación, se expone el enfoque conceptual adoptado para avanzar en el estudio del caso, seguido de la descripción metodológica. Posteriormente, se presentan los resultados alcanzados organizados desde una perspectiva temporal. Finalmente, las conclusiones recuperan los hallazgos más relevantes sobre Chascomús para ponerlos en discusión, y aportar a la construcción de una mirada crítica sobre la ciudad actual.

\section{MARCO TEÓRICO}

Abordar conceptualmente la relación entre las dimensiones históricas, sociales y físicas que interpelan a la ciudad exige comenzar por reflexionar en torno a la complejidad inherente al espacio urbano: un espacio físico que es socialmente construido; que asume una materialidad pero que también porta un valor simbólico y cultural que lo constituye históricamente; que contiene una lógica de circulación del poder y expresa las pautas hegemónicas y contra-hegemónicas del habitar. También alude a un territorio que es contexto, condición y producto de las relaciones sociales de producción. Junto al medio ecológico debe reconocerse el entramado de actores con sus lógicas de disputa, coalición y su particular capacidad de incidir: instituciones, infraestructuras, estructuras y procesos.

Recuperamos así las miradas clásicas del espacio urbano como las de Soja (1997/2000), que en perspectiva Lefebvriana advierte sobre la "trialéctica de la espacialidad" para referir al equilibrio de los tres aspectos fundamentales que sostienen a los hechos y al ser: la historicidad, la socialidad y la espacialidad. Finalmente, también reconocemos la reflexión de Milton Santos (2009) sobre la cuestión, considerando al espacio como una instancia de la sociedad, al mismo nivel que la instancia económica y la instancia cultural-ideológica. En tanto que instancia, el espacio contiene y está contenido por las demás instancias, del mismo modo que cada una de ellas lo contiene y es por ellas contenido. La economía está en el espacio, así como el espacio está en la economía. Lo mismo ocurre con lo político-institucional y con lo cultural-ideológico.

Con este acercamiento, la aproximación histórica a la ciudad, sus formas y dinámicas de cambio en el tiempo nos ha llevado a reconocer ciertas unidades de sentido que configuraron diferentes formas de crecimiento urbano a lo largo del tiempo. Se identifican así diversos modelos de ciudad que expresan cierta congruencia entre sistema productivo, arreglo político-institucional, paradigma urbano (con sus instrumentos normativos) y patrón espacial. Esa unidad de sentido en el escenario latinoamericano ha llevado a reconocer diferentes fases de la urbanización, organizadas en torno al modelo de ciudad colonial, ciudad industrial y ciudad post-fordista -con base empírica en su mayoría en las grandes áreas metropolitanas²-. El soporte físico, en concordancia, ha asumido una estructura urbana también particular; con un momento inicial de ciudad compacta (con un patrón de segregación anular), posteriormente de ciudad sectorial (con proceso de expansión urbana siguiendo ejes de comunicación) y luego, de ciudad polarizada o fragmentada (bajo un patrón celular perdiendo conexión con la mancha urbana) (Janoschka, 2002; Borsdorf, 2003; Bähr \& Borsdorf, 2005).

2. En cuanto a la ciudad mediana latinoamericana se destacan los trabajos de Mertins (2000), quien propone un modelo urbano general para analizar la diferenciación socio-espacial y funcional en cada etapa de transformación urbana. 
Con lógica similar, esa unidad de sentido entre modelo de acumulación, arreglo institucional y forma de la ciudad también puede ser comprendida atendiendo a la morfología urbana y, dentro de ésta, al rol otorgado al ambiente y los recursos naturales; aspectos asimismo considerados en nuestro estudio. Tal como sostiene Capel (2002) “La morfología urbana, el espacio construido, refleja la organización económica, la organización social, las estructuras políticas y los objetivos de los grupos sociales dominantes" (p. 20). Reconocemos, al igual que el autor, al plano -con su trama viaria y parcelario-, los edificios y los usos del suelo, como los elementos básicos que configuran el tejido urbano.

Por último, resta aclarar que la lectura temporalmente lineal de la historia de la ciudad no debe llevarnos a desconocer la existencia de tendencias complejas, y a veces contradictorias que la atraviesan. Avanzar entonces en el estudio de la forma urbana exige también reconocer al espacio urbano que se produce y reproduce permanentemente como palimpsesto; borrando, reciclando y reescribiendo lo que ya existe (Corboz, 2004). Ciudad y territorio que observa tantas interpretaciones y definiciones como disciplinas y campos, y que observa la intersección de diferentes temporalidades, con sus paradigmas urbanos y dinámicas económicas de producir la ciudad. Volviendo una vez más a Capel (2002) es misión del especialista descubrir y reinterpretar dichas huellas del pasado, que aparecen siempre a la mirada atenta del observador. Proponemos entonces avanzar en el análisis de la morfología urbana, sus contextos y cambios a través del tiempo, como forma de entender las unidades de sentido que configuraron la historia de una ciudad intermedia. Con ello, procuramos identificar dinámicas de crecimiento generales presentes en la ciudad latinoamericana -y sus diferentes fases de urbanización-, las particulares de las ciudades intermedias, y las específicas propias del caso local de estudio. Frente a esto último, concedemos particular atención al impacto sobre la dimensión ecológico-ambiental.

\section{METODOLOGÍA}

Avanzamos en el estudio de la forma y dinámica territorial de una ciudad mediana latinoamericana a partir del caso Chascomús, ciudad cabecera del partido homónimo localizado en la margen este de la Provincia de Buenos Aires (PBA), Argentina. Este último, en concordancia con las características de los partidos del interior bonaerense (y en oposición a lo que sucede con los partidos metropolitanos), posee una gran extensión, con 3.193 km2 y muy baja densidad, con una población de 36.647 habitantes. Por su parte, la ciudad de Chascomús se localiza en relación directa con la Laguna de Chascomús ${ }^{3}$ concentrando aproximadamente un 91 \% de la población total del partido: 33.607 habitantes según datos del Censo Nacional de Población y Vivienda (INDEC, 2010).

Si bien se encuentra por fuera de los continuos urbanos de la Ciudad Autónoma de Buenos Aires (CABA) y la Ciudad de La Plata, posee una elevada accesibilidad a los mismos, fundamentalmente a través de autopistas (figura 1). La Ruta Nacional № 2 atraviesa el partido en sentido norte-sur y lo conecta al norte con la Ciudad Autónoma de Buenos Aires (mayor centro urbano de la Argentina) y la ciudad de La Plata (capital de la provincia de Buenos Aires), y al sur con la Ciudad de Mar del Plata (ciudad balnearia más importante de la costa atlántica argentina). La Ruta Provincial 20 también atraviesa el Partido en sentido oeste-este y conecta a la ciudad con otros centros relevantes de la Región. También existe la línea Ex Roca de Ferrocarril que lo conecta con la CABA, Mar del Plata y Pinamar, aunque con una regularidad muy baja.

El partido conforma un territorio fluvial compuesto por una gran diversidad de recursos hídricos: lagunas, gran cantidad de arroyos y el Río Samborombón al noreste, que opera a su vez como límite jurisdiccional. Se localiza en la cuenca del Río Salado, en una zona donde predomina la llanura pampeana con escasa pendiente de suelo. Esta ubicación lo articula, por un lado, con el ecosistema de pastizal pampeano, históricamente intervenido y degradado por la actividad agrícola y ganadera predominante en la región desde

3. Laguna principal de un sistema de siete lagunas encadenadas compartido al sur con el Partido de Lezama (Hasta el año 2009 ambos partidos conformaban una unidad administrativa: Partido de Chascomús). 
el SXIX. Por otro lado, lo integra al ecosistema de humedales, intervenido y afectado fuertemente desde la década del noventa por las prácticas urbanas y las rurales extensivas.

La estrategia metodológica para el estudio de la ciudad de Chascomús se organiza en torno a una primera periodización del proceso de conformación (1779-2021) desde un abordaje histórico-ambiental y contextualizado en el interior de la provincia de Buenos Aires, reconociendo así un proceso común a la red de ciudades que hoy conforman la Provincia de Buenos Aires. Dicha periodización, determinada a partir de la sistematización de fuentes primarias y secundarias sobre hechos y/o acciones que produjeron cambios en los usos de suelo, los tejidos y la explotación del territorio, sirvió de base para analizar el crecimiento del edificado en la ciudad.

Posteriormente, se complementó el análisis diacrónico indagando sobre el crecimiento de la matriz edificada y siguiendo la metodología planteada por Solá Morales (1997): cómo las fases de parcelación, urbanización y edificación se combinaron en el tiempo y el espacio. Para ello se construyó una representación gráfica de la evolución de la mancha edificada en cada momento de la periodización a partir de documentos históricos, planos y vuelos. Para el primer corte en 1830 se tuvieron en cuenta los planos realizados por los agrimensores Juan Saubidet (1825-1826) y los redibujos realizados por De Paula (2000) y Aliata (2010), en conjunto con registros gráficos de la PBA elaborados por el Departamento Topográfico (Carta de la PBA, 1824 y Carta Geográfica de la PBA, 1829) en el que se da cuenta de los caminos existentes. El segundo corte en 1905 se basó en el plan de Jaime Arrufó (1855) y el plano de catastro de Chascomús de 1905, y fueron de especial aporte una serie de postales y fotografías de la época obtenidas en el mismo Museo. El corte de 1930 se construyó a partir de datos históricos e información proveniente de la Municipalidad en conjunto con postales urbanas y fotografías de la época. Para los cortes de 1965 y 1985 se utilizaron las imágenes correspondientes a vuelos disponibles en la Dirección de Geodesia de La Plata y también se tuvo acceso a imágenes correspondientes a un vuelo de 1984 provisto por la Municipalidad. Por último, el corte de 2015 se realizó a partir de la imagen satelital extraída de google earth correspondiente a enero de 2016, y el corte de 2021 con la correspondiente a abril de 2021. Por su parte, la forma de la Laguna y arroyos presentados en los gráficos surge de la imagen satelital de 2015 por no existir registros completos sobre sus cambios a lo largo de la historia del asentamiento.

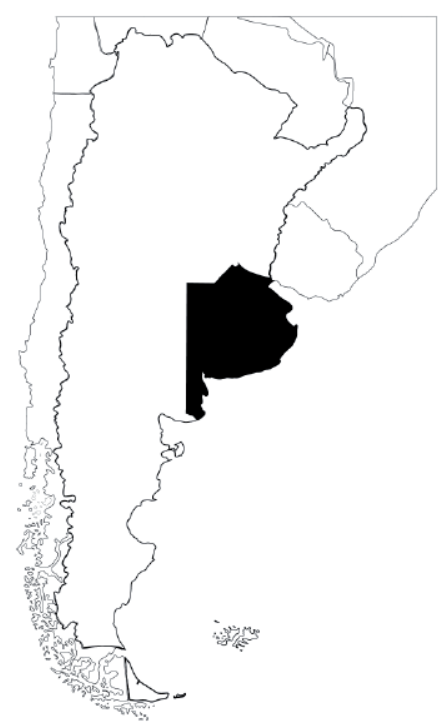

ARGENTINA - PROVINCIA DE BUENOS AIRES
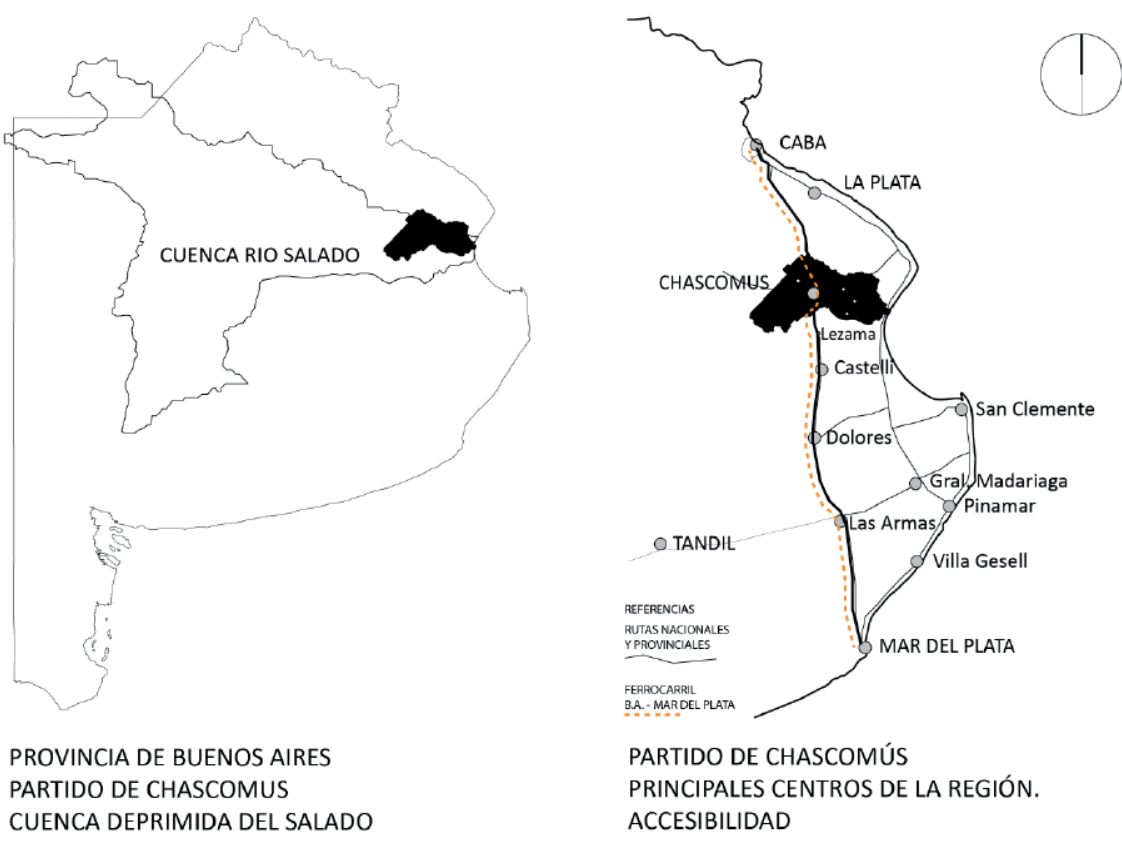

Figura 1. Localización del caso de estudio. Fuente: Giusti, 2021. 
El registro de los cambios a partir de documentación histórica, imágenes aéreas y satelitales, en conjunto con trabajos de campo y relevamiento permitió "espacializar" los cambios físicos y de usos de suelo del territorio y complejizar la mirada sobre los procesos. La interpretación y redibujo a partir de diversas fuentes en paralelo al análisis histórico-ambiental, nos permitió comprender y dar a conocer cómo se dieron los procesos de transformación del territorio y su complejidad, para determinar la existencia de tres tendencias en los modelos de expansión residencial.

\section{RESULTADOS Y DISCUSIÓN}

Para introducir a los cambios que se produjeron en la forma de la expansión de la ciudad de Chascomús y sus tendencias de crecimiento es necesario figurar cuáles eran las características iniciales del territorio donde se localizó su fundación en 1779, y la estructura germinal del plan sobre el que iniciarían luego las tres tendencias de crecimiento: completamiento y compactación de su tejido urbano; ensanche y dispersión de la traza; y extrema dispersión y densificación del tejido.

Recién en 1776, con la creación del Virreinato del Río de la Plata, Buenos Aires cobra importancia político-administrativa y activa su Puerto, en ese momento predominaba el paisaje natural integrado por los ecosistemas del pastizal pampeano y del humedal ${ }^{4}$. Es a partir de 1779 que el territorio de Buenos Aires queda delimitado con la construcción de una línea de defensa de casi 500 kilómetros con once puestos militares al norte del Río Salado: hacia el norte la "civilización" y hacia el sur el territorio desconocido e inexplorado, "la barbarie", el "desierto". Los puestos se construyen con el objeto de asegurar a Buenos Aires de los pueblos originarios y proteger a los españoles que se encontraban en parajes apartados.

El "Fuerte de San Juan Bautista de Chascomús" conformó uno de esos puntos localizándose en cercanía con la Laguna de Chascomús 5 . La presencia de recursos hídricos, si bien reconocidos en la toponimia de muchas de las fundaciones, no fueron inicialmente incorporados a las composiciones fundacionales. Sí, se garantizaba la cercanía a los mismos en tierras altas empleándolos como fuentes de recursos primarios y aprovechándolos como defensa por conformar accidentes geográficos ante la infinita extensión del vasto territorio en disputa. Aunque no existe documento que refiera al trazado fundacional del Fuerte de Chascomús, éste debió responder a las disposiciones de las Leyes VIII, IX, y X del Libro IV de la Recopilación de Indias; en ellas la plaza fundacional conformaba el foco de la vida social a partir de la cual se organizarían el Fuerte, la Iglesia y otros edificios de importancia Institucional, cultural y social.

Con un desarrollo muy precario y desordenado de las fundaciones es recién a partir de la Independencia en 1816 que se intenta promover el poblamiento de las guardias, cuyo éxito llega a partir de la conformación en 1824 del Departamento Topográfico, un Organismo de Gobierno que se ocupó de ejecutar las tareas de registro y orden de las fundaciones y desplegar estrategias territoriales (suertes de estancia, enfiteusis ${ }^{6}$, colonización ejidal, entre otras) ante la necesidad nacional de expandir el territorio y organizar su explotación con ganadería. La fundación de ciudades como la chascomunense resultó, entonces, un medio para el "progreso" y no un resultado del mismo.

\subsection{Primeros planes: completamiento y compactación (1826-1945)}

Los agrimensores fueron los técnicos protagonistas del proceso de colonización a partir de ciudades, y a Chascomús llegan en dos oportunidades. Una primera en 1825 cuando el Oficial Juan Saubidet registra en

4. La actividad agraria extensiva que actualmente caracteriza el paisaje cultural de la pampa húmeda no existió hasta fines del SXIX.

5. Toponimia en mapuche para "agua muy salada".

6. Sistema de alquiler de tierras fiscales sancionada el 18 de mayo de 1826 por el primer Presidente de las Provincias Unidas Bernardino Rivadavia (1826-1827). 
sus planos la existencia del pueblo, regulariza su trazado y crea la Comisión de Solares ${ }^{7}$. En su propuesta define los límites de la ciudad con el ejido a partir de dos avenidas de circunvalación - actuales Lastra y Tte. Gral. Juan Domingo Perón. Cabe aclarar que luego de la independencia argentina y en manos del Departamento Topográfico, el ejido cobra un nuevo sentido convirtiéndose en un espacio agrícola conformado por quintas (huertos) y chacras (granjas) destinadas al aprovisionamiento local. El ejido bonaerense junto con el pueblo o ciudad conformaban una unidad "ciudad-agricultura" fundamental para el objetivo de arraigo deseado y la explotación económica del territorio conquistado.

El segundo agrimensor Jaime Arrufó llega en 1855, una vez constituido el estado nacional. En treinta años el pueblo había crecido respetando el primer plano, pero sobrepasando sus límites en algunos sectores o avanzando sobre los espacios públicos, especialmente en la zona central. El nuevo plano además de la re-delimitación de la propiedad privada y pública (Aliata, 2010), extendió el trazado con un amanzanamiento de proporción cuadrada (100 varas); conservó los bulevares -en parte-, ante el pedido de vecinos de que dichas avenidas no "se dividiesen en cuadrilongos" (Arrufó 1855, citado por Aliata 2010); y redefinió los límites del ejido. La principal intromisión a dicho plan se efectivizó después, con la llegada del Ferrocarril en 1865. El nuevo rol como punta de rieles posicionó a Chascomús como centro de servicios de la Región y potenció la consolidación de población y el crecimiento del pueblo. Inicialmente la estación se localizó en el extremo noroeste y conformó un segundo centro en la composición del tejido. Posteriormente, la extensión de la traza hacia el sureste en 1874, rompió el tejido planificado absorbiendo el paso del tendido sin una propuesta particular para el sector. La ciudad continuó creciendo sobre la base del plano de 1855 llegando al completamiento casi un siglo después, aproximadamente en 1945 (figura 2).

Los procesos que se dieron en ese período respondieron al afianzamiento del modelo nacional agroexportador: "poblar, controlar y producir" (Pesoa, 2016, p. 89), para luego exportar. Es así que los ecosistemas naturales, principalmente el pastizal pampeano del partido, resultaron profundamente alterados a partir de las actividades agrícolas extensivas; más aún con el uso masivo del Ferrocarril y el alambrado, quedando en la actualidad muy pocos reductos en el contexto bonaerense. Como puede constatarse en la tabla 1, el afianzamiento del modelo también implicó una serie de políticas inmigratorias que aportaron a Chascomús, principalmente con la llegada del Ferrocarril, la llegada de nueva población para explotación rural con fuerte presencia de comunidades extranjeras de diverso origen. Estas, inyectaron nuevos usos y costumbres y nuevas instituciones culturales y sociales que resultaron fundamentales en la consolidación de la ciudad.

Tabla 1. Población urbana de Chascomús (1780 a 1914).

\begin{tabular}{|c|c|c|c|c|}
\hline Año & Población (hab.) & $\begin{array}{c}\text { Variación relativa } \\
(\%)\end{array}$ & $\begin{array}{c}\text { Cantidad de años } \\
\text { entre datos }\end{array}$ & $\begin{array}{c}\text { Tasa de crecimiento medio anual } \\
\text { (C/1000 Hab.) }\end{array}$ \\
\hline 1780 & 374 & - & - & - \\
\hline 1782 & 411 & 10 & 18 & 58,3 \\
\hline 1800 & 1.000 & 143 & 15 & 29,7 \\
\hline 1815 & 1.551 & 55 & 21 & 40,7 \\
\hline 1836 & 3.586 & 131 & 18 & 15,4 \\
\hline 1854 & 4.723 & 32 & 15 & 48,7 \\
\hline 1869 & 9.637 & 104 & 27 & 11,3 \\
\hline 1896 & 13.044 & 35 & 18 & 12,8 \\
\hline 1914 & 16.392 & 26 & & 27 \\
\hline
\end{tabular}

Fuente: Giusti, 2021.

7. Responsable de ordenar clarificando los títulos de propiedad, otorgando en merced o enfiteusis, loteos urbanos, chacras y quintas (Aliata, 2010, p.28). 

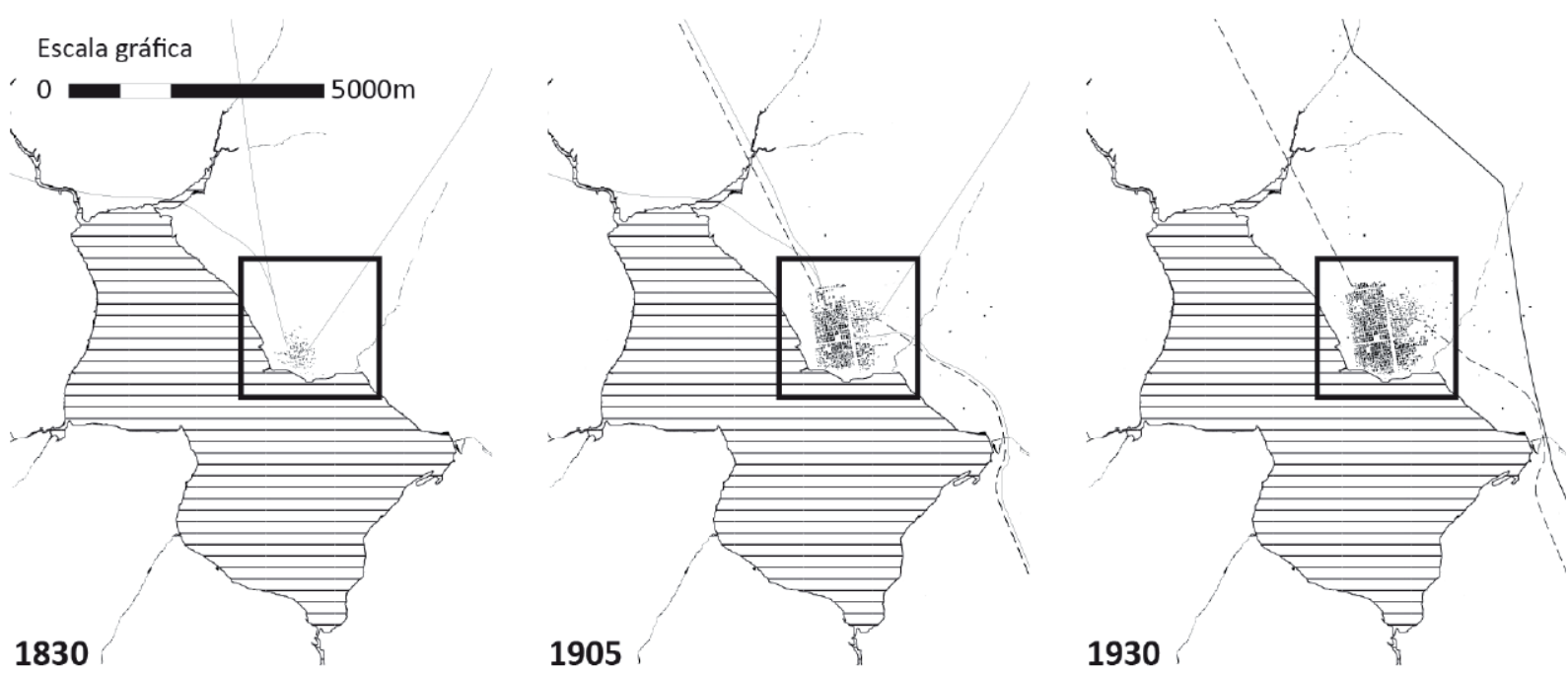

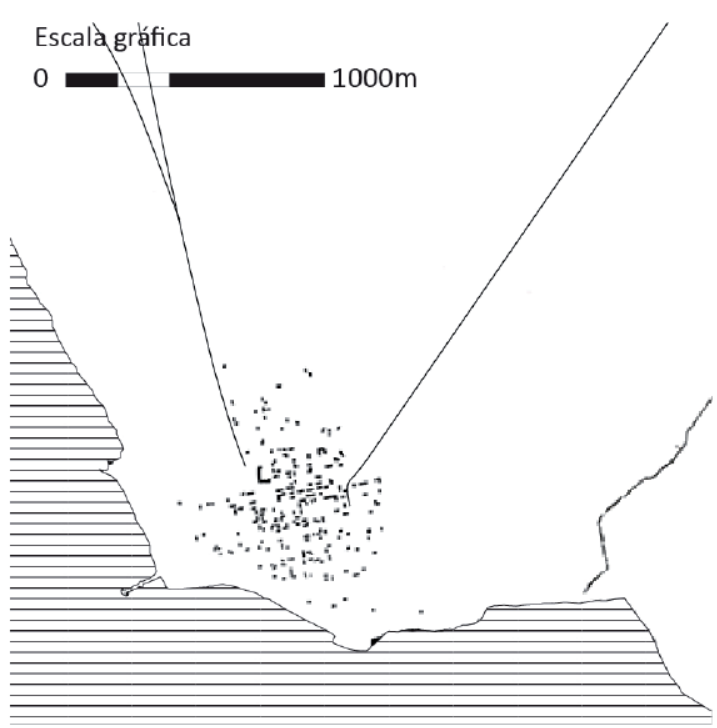

1830

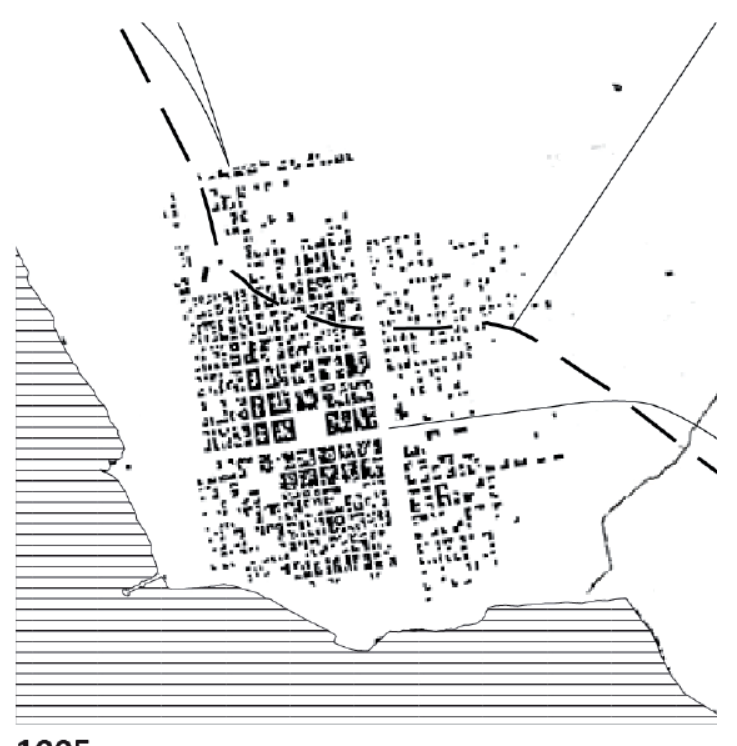

1905
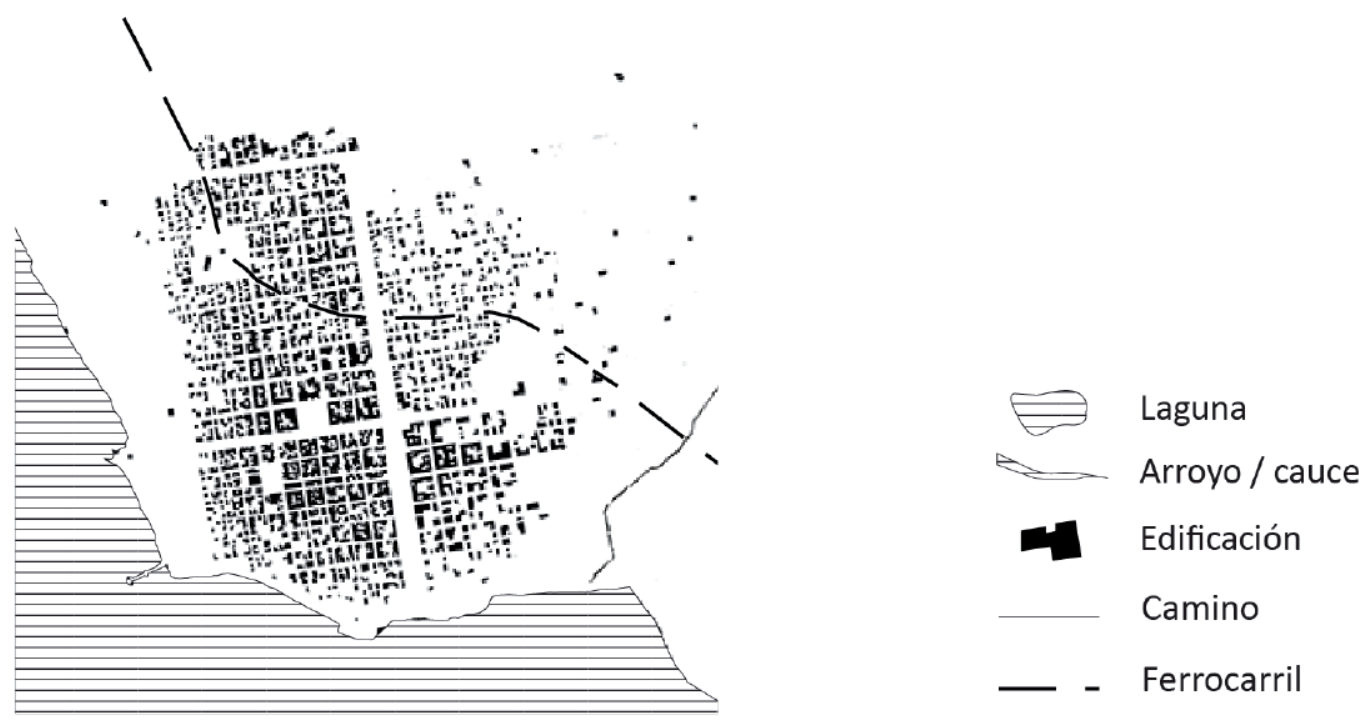

1930

Figura 2. Completamiento y compactación (1779-1945). Fuente: Giusti, 2021. 
La crisis mundial de la década del treinta repercute en el modelo económico agroexportador argentino el cual comienza a virar gradualmente a un esquema de sustitución de importaciones. Sin embargo, esto no impacta rápidamente en la Ciudad de Chascomús, como sí lo hace la aparición en 1932 de la Dirección Nacional de Vialidad y con ella, una nueva estrategia de integración territorial. Con participación de sectores públicos y privados se construyeron una serie de rutas, no solo con el objetivo de conectar a los centros productivos entre sí o de resolver cuestiones de vialidad, sino de potenciar el uso del automóvil y con ello el turismo (De Laurentis, 2014). La pavimentación de la actual Autovía Nº 2 en 1938 dinamiza la actividad turística en el partido con foco en Chascomús. La tríada turismo, automóvil y caminos produjo en la ciudad un cambio en la explotación de los recursos naturales y en la estructura urbana con la laguna como protagonista. Esta pasó de ser medio para la provisión de recursos primarios y evacuación de efluentes a espacio recreativo, de ocio y contenedor de nuevas prácticas. De esta forma, el sector Costanero relacionado directamente con el tejido urbano es revalorizado e intervenido a la vez que se ejecuta un camino de circunvalación de toda la Laguna. En coincidencia con los festejos del centenario de la "Batalla de los Libres del Sur" (1839-1939)' se dan una serie de intervenciones urbanas destinadas tanto al embellecimiento del centro fundacional ${ }^{8}$, como a la promoción de este nuevo vínculo con la Laguna según el paradigma de la época: Parque Libres del Sur, Museo Pampeano, Paseo Costanero, Balneario Municipal, Fomento y Turismo y Edificio del Turista. A estas obras se suma, a fines de los cuarenta, la aparición de una nueva modalidad de acceso a la tierra destinada a pequeños ahorristas a partir del fraccionamiento y subdivisión de chacras y quintas del ejido. Denominados "loteos populares", eran desprovistos de infraestructuras y comercializados desde los grandes centros urbanos a modo de inversión (con pago por mensualidad). La edificación en los mismos, sin embargo, se dará mucho más adelante.

La primera tendencia de expansión de la matriz edificada queda por tanto definida temporalmente entre su fundación en 1779 y aproximadamente el año 1945 (figura 3). Se caracteriza por el completamiento y compactación de los planes ejecutados por el Departamento Topográfico en 1826 y en 1855 a lo que se suma un primer ensanche hacia la Laguna de Chascomús a finales del período. Los elementos formales-paisajísticos que la constriñen son los Bulevares Escribano e Hipólito Irigoyen y la Laguna de Chascomús. Si bien en la totalidad del sector predomina una densidad medio-baja propia de las ciudades de baja densidad de la región, al interior de esta tendencia encontramos la existencia de tres sectores bien definidos en función del momento de su consolidación y de las características de su tejido (figura 3). En cuanto a las características generales de esta primera tendencia, el tejido es compacto con un alto grado de consolidación urbana determinada por la provisión de infraestructuras básicas, equipamientos y servicios con existencia de lotes vacantes. El espacio verde público posee una gran potencialidad ${ }^{9}$ en el sector, aunque se encuentra poco jerarquizado y desprovisto de funciones definidas; lo que genera un bajo uso cotidiano y la sobreexplotación de los localizados en relación con la Laguna.

\subsection{Ensanche y dispersión de la matriz edificada: loteos populares, crecimiento espontáneo irregular y barrios parque (1946-1989)}

Entre los años 1946 y 1989 sobreviene el ensanche y dispersión de la matriz edificada de la Ciudad. Si bien dicha tendencia es la predominante para el período, coexiste junto con otros procesos como el de completamiento y compactación del trazado del plan Arrufó a partir de una mayor subdivisión de sus lotes originales. Inicialmente la dispersión se presenta a modo de ensanche invadiendo el ejido contiguo a la ciudad, es decir,

8. Entre otros, la construcción del Palacio Municipal en manos del Arq. Francisco Salamone (iniciado en 1939 y finalizada en 1941), empedrados, luminarias y nuevos monumentos como el Reloj de los Italianos.

9. Su potencialidad radica en la gran cantidad y diversidad de tipos de elementos: Plaza Independencia, Plaza Libertad, Plaza Sarmiento, Plaza Gouaillard, arbolado viario, ramblas, plazoletas, Parque de los Libres del Sur, Parque Centenario y Parque de los inmigrantes, Bulevares Lastra, Hipólito Irigoyen y Escribano y los sectores verdes y públicos de la "peri laguna". 
por fuera de los Bulevares que operaban originalmente como límite. Luego, se localiza en relación a los dos ejes de acceso a la Ciudad desde la Autovía No 2 (Av. J.M. Rosas y Av. Lastra). Las condiciones de llanura permitieron la expansión a través de la continuidad del damero, aunque con limitaciones naturales y físicas: la laguna, los arroyos y las zonas inundables, por un lado; y las infraestructuras del Ferrocarril, la ruta Provincial $^{\circ} 20$ y la Autovía $N^{\circ} 2$, por el otro. A partir del fomento del turismo con foco en el recurso lagunar, el ensanche iniciado entre la década del cuarenta y el cincuenta se acopló al área central, dando continuidad al amanzanamiento, pero con parcelamientos de mayor tamaño incorporando las edificaciones de inicios de siglo. Mientras tanto, con la llegada de la industria se deslocalizó la edificación a nuevos sectores.
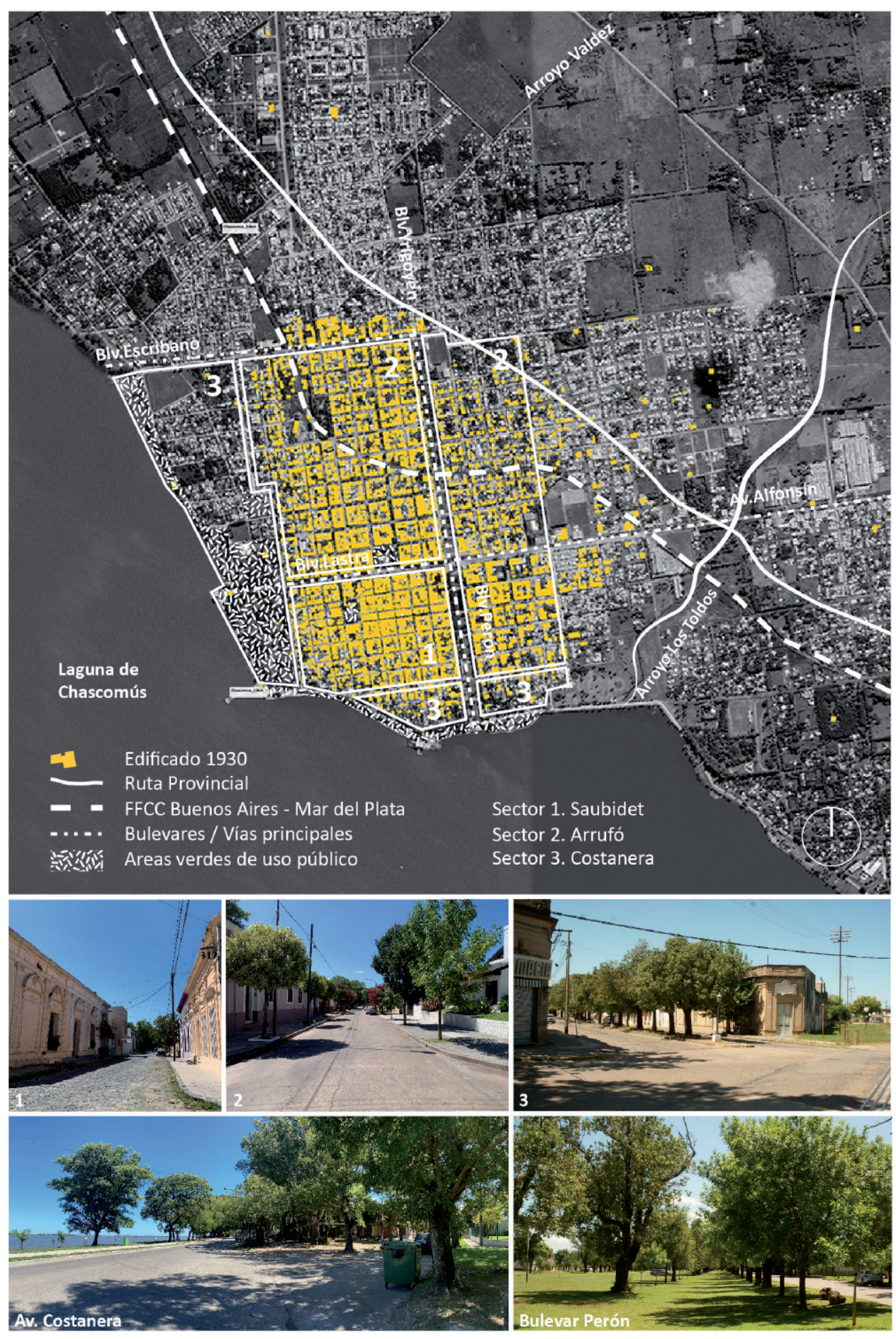

Figura 3. Primera tendencia de expansión urbana (Sectores homogéneos, paisajes y límites). Fuente: Elaboración propia sobre base satelital de Google 2020. 
El modelo industrial de sustitución de importaciones llegó a Chascomús de forma tardía. Aunque con cierta presencia desde la década del cincuenta, la actividad no se consolidó hasta los sesenta y los setenta, con el sector metalúrgico, textil y alimenticio derivado de productos de la agricultura y la ganadería. Las fábricas se localizaron de forma periférica, hacia el este del centro fundacional y en relación directa con el Arroyo Los Toldos y la Av. Lastra/ Pte. Alfonsín (acceso secundario a la ciudad desde la Autovía № 2).

Esta nueva dinámica productiva imprimió marcas en el territorio con alcances sobre la sustentabilidad urbana. Por un lado, la descarga de efluentes industriales en el arroyo Los Toldos impactó sobre su función ambiental. Éste recoge naturalmente el excedente de agua del territorio y lo conduce a la Laguna de Chascomús; y ésta, al Sistema de Lagunas encadenadas. Su contaminación por lo tanto incide sobre todo el sistema hídrico del que forma parte. Por el otro, la actividad industrial promovió la edificación en sus alrededores materializada a partir del crecimiento espontáneo irregular y, principalmente, la edificación de los loteos populares parcelados veinte o treinta años antes (tabla 2). Bajo esta misma modalidad se produjeron nuevas edificaciones residenciales hacia el noroeste del centro fundacional, en torno a la Av. J.M. de Rosas - vía principal de acceso a la ciudad-. A partir de la década del ochenta, sobre este último corredor se suma la ejecución de una serie de planes de vivienda financiados por el Estado Provincial, que no lograron tener el impacto de los loteos populares (tabla 3). Por tanto, ambos accesos a la ciudad terminaron conformando los dos ejes de crecimiento de la mancha urbana a partir de un patrón extensivo de baja densidad con un posterior completamiento intersticial (figura 4).

Otra modalidad derivada de los loteos populares fueron los "barrios parque", que aparecen en el conurbano bonaerense como loteos para viviendas de fin de semana para los porteños. En Chascomús surgen de forma extraurbana asociados a la Laguna. La primera experiencia de parcelamiento coincide temporalmente con su presencia masiva en el conurbano (Gómez Pintus, 2013). En 1948 se parcela el Barrio Parque Girado; en 1969, el Barrio Lomas Altas; y en 1973, Barrio Liberatta. En coincidencia con los loteos populares vinculados a la ciudad, su edificación aparece de forma muy tardía. Esto puede constatarse en la figura 4 para el año 1985, donde sobre la laguna y en el sector opuesto a la ciudad se inicia la edificación del Barrio Parque Girado.

Cabe destacar que estos procesos de expansión -principalmente la fase de parcelamiento-, se inician sin un plan vigente para la ciudad. Recién en 1977 surge para la Provincia de Buenos Aires el Decreto Ley № 8912 de Ordenación de usos del suelo ${ }^{10}$, el cual es instrumentado localmente recién en 1981 a partir de la Ordenanza N 1.272 conocida como Plan Regulador de Chascomús (PR). Este conformó un instrumento normativo que formalizó las tendencias existentes sin una visión local crítica e integral. En tanto luego de su legislación, la expansión de la edificación continuó sus tendencias formalizadas en la nueva normativa.

Entonces, los principales agentes de expansión de este período fueron el sector privado, a partir de los loteos populares -hacia el este, en anexiones discontinuas o completando intersticios-; y el Estado Provincial, a partir de planes de vivienda (IVPBA) -hacia el norte y noroeste-. Los primeros incorporaron nuevas tipologías de tejidos, fueron ejecutados sin infraestructuras de servicios ni equipamientos, sin conectividad entre los barrios y en sectores de riesgo ambiental; complejizando y encareciendo la posibilidad de una futura consolidación urbana con accesibilidad y movilidad. Los segundos, aunque con una mejor dotación de infraestructuras, lo hicieron desprovistos de equipamientos sociales y espacio público de calidad. La ausencia de previsión de plazas, parques, espacios libres, equipamientos de uso comunitario y calles consolidadas imposibilitaron la existencia de sub-centros de escala barrial afectando la posibilidad de fortalecer los entramados sociales e identidades de los nuevos barrios. Estas características de la expansión terminaron reafirmando una estructura centro-periferia aún vigente con grandes diferencias socio-económicas, ambientales, paisajísticas y de accesibilidad (figuras 5 y 6).

10. Normativa de usos del suelo de la Provincia de Buenos Aires, con mismas regulaciones para municipios del interior y municipios participantes de la conurbación de la ciudad de Buenos Aires. 
Tabla 2. Loteos populares y barrios parque entre 1945 y 1975.

\begin{tabular}{|c|c|c|c|}
\hline Año & Cantidad de lotes & Referencias y Localización & Barrio actual \\
\hline 1947 & 269 & Frente a la policía caminera & SN \\
\hline \multirow{6}{*}{1948} & 307 & $\begin{array}{l}\text { Parque Girado (tipo Barrio Parque) Al otro lado de la } \\
\text { ciudad, en los bordes de la laguna }\end{array}$ & Parque Girado \\
\hline & 239 & Frente a Atalaya Al este de la Ruta 2 & SN \\
\hline & 152 & Caballo Blanco Prolongación de Lastra y Garay & Anahí \\
\hline & 60 & Loteo Pedro Escribano (loteos aproximados) & Villa Luján \\
\hline & 140 & $\begin{array}{l}\text { Chacra Gelsi Frente a Av. Lastra (falta localización } \\
\text { exacta) }\end{array}$ & \\
\hline & 228 & $\begin{array}{l}\text { Chacra de Inchauspe Escribano, Machado, Arenaza, } \\
7 \text { de noviembre y Casalins. Loteos aproximados }\end{array}$ & Villa Luján \\
\hline \multirow{2}{*}{1949} & 532 & Zona el Castillo & SN \\
\hline & 367 & Frente a CONARCO & SN \\
\hline 1952 & 717 & Barrio Martin Fierro Frente a San Cayetano & San Nicolás \\
\hline 19651967 & 1890 & San Cayetano Av. Rosas y Ruta 2, Arroyo Valdés & San Cayetano \\
\hline 1968 & 598 & $\begin{array}{l}\text { Bajos del Cementerio Detrás del actual Howard } \\
\text { Johnson }\end{array}$ & Los Aromos \\
\hline 1969 & 1458 & $\begin{array}{l}\text { Barrio Lomas Altas (tipo Barrio Parque) Borde de la } \\
\text { laguna. Lado contrario a centro fundacional }\end{array}$ & Barrio Lomas Altas \\
\hline 1973 & 178 & Barrio Parque La Liberatta (tipo Barrio Parque) & La Liberatta \\
\hline- & 7135 & - & - \\
\hline
\end{tabular}

Fuente: Giusti, 2021.

Tabla 3. Intervenciones de vivienda financiadas por el Estado entre 1984 y 1989.

\begin{tabular}{|c|c|c|c|c|}
\hline Año & Cantidad de Viviendas & Identificación/ Plan & Barrio & Zona \\
\hline 1984 & 26 & Instituto de Viviendas. PBA & Villa Luján & Norte \\
\hline \multirow{2}{*}{1986} & 139 & Instituto de Viviendas. PBA & Acceso Norte & Norte \\
\hline & 10 & Autoconstrucción 1 & Iporá & Este \\
\hline \multirow{3}{*}{1989} & 18 & Autoconstrucción 2 & Baldomero Fernández Moreno & Sur Este \\
\hline & 19 & Plan de Viviendas Progresivas & Baldomero Fernández Moreno & Sur Este \\
\hline & 14 & Procasa 1 y 2 & Baldomero Fernández Moreno & Sur Este \\
\hline- & 226 & - & - & - \\
\hline
\end{tabular}

Fuente: Giusti, 2021. 

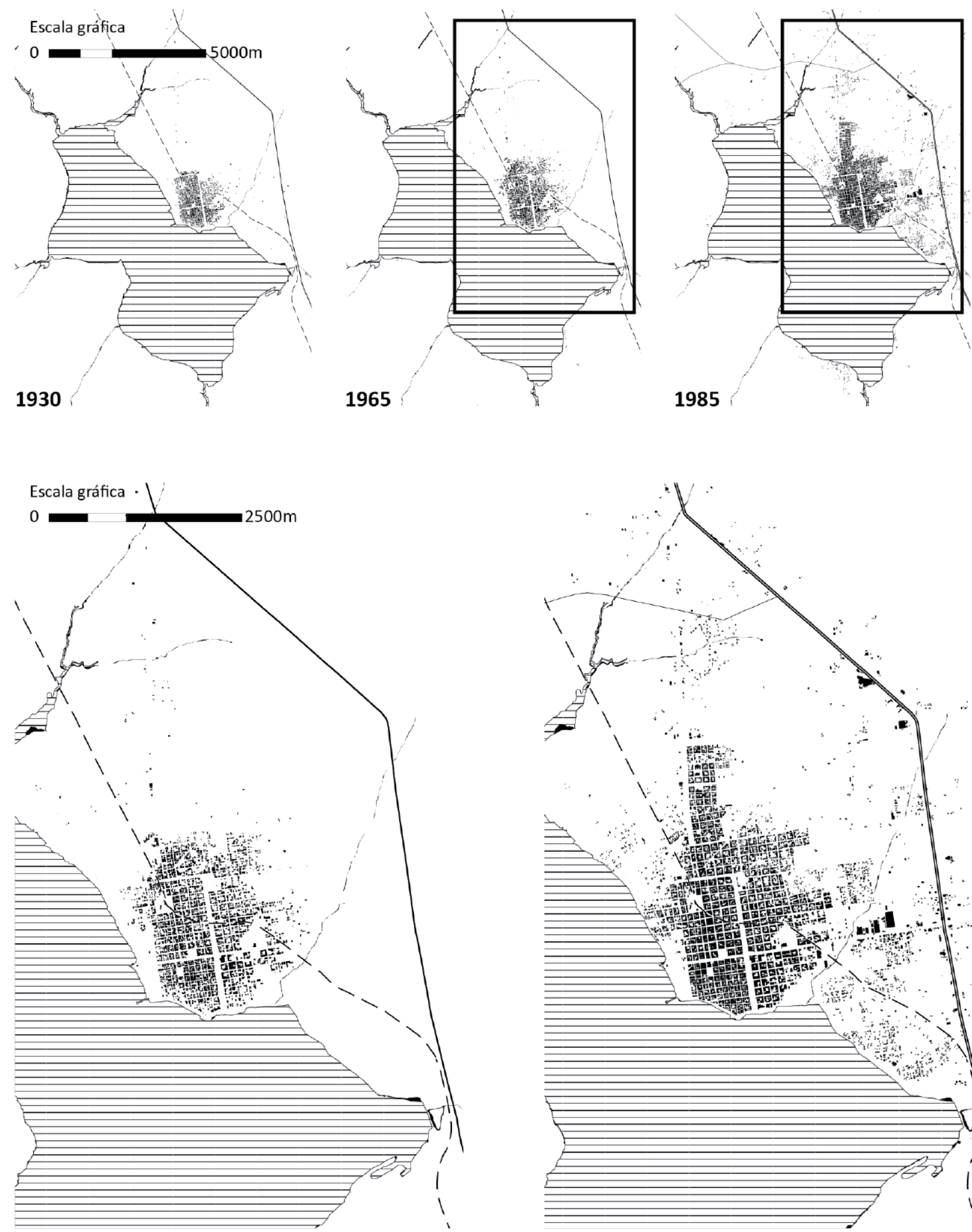

1965

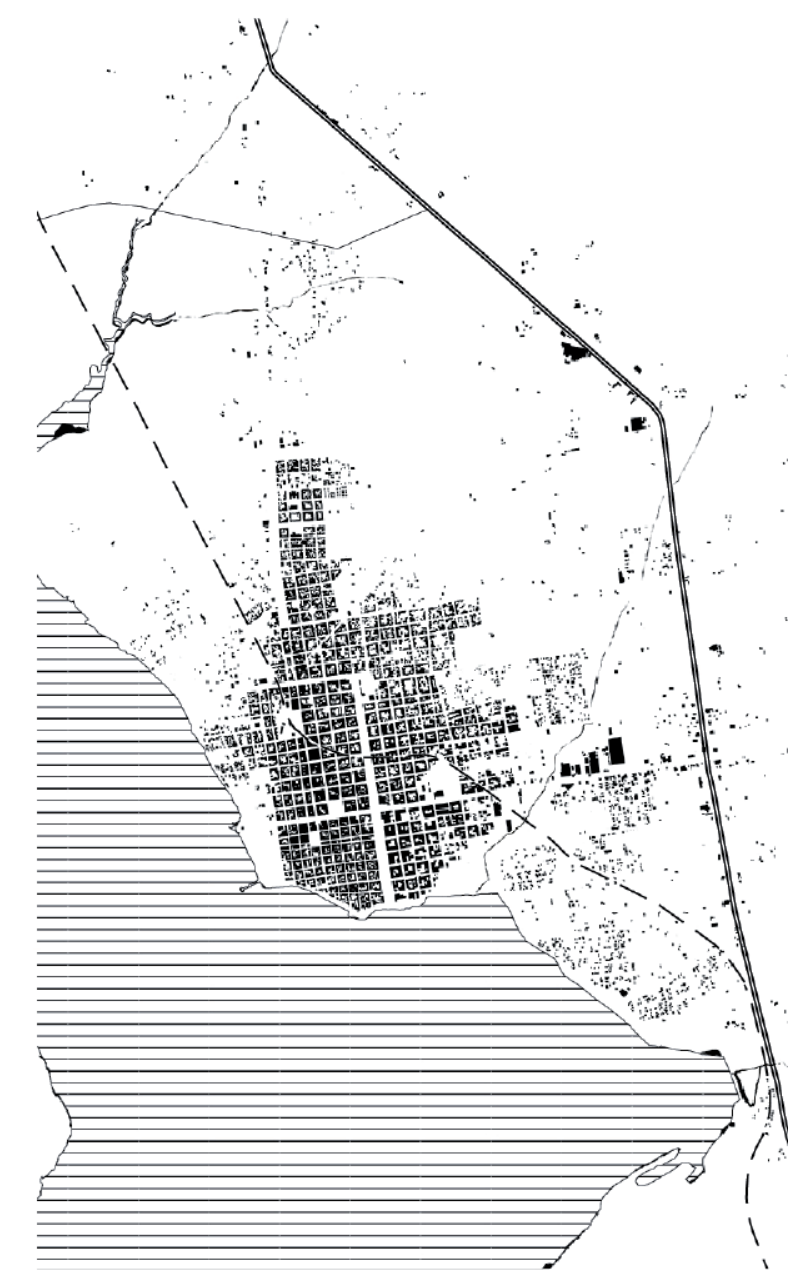

1985

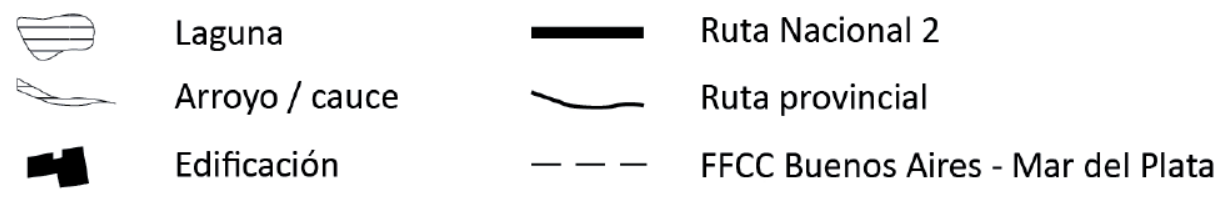

Figura 4. Ensanche y dispersión de la matriz edificada (1946 - 1989). Fuente: Giusti, 2021. 

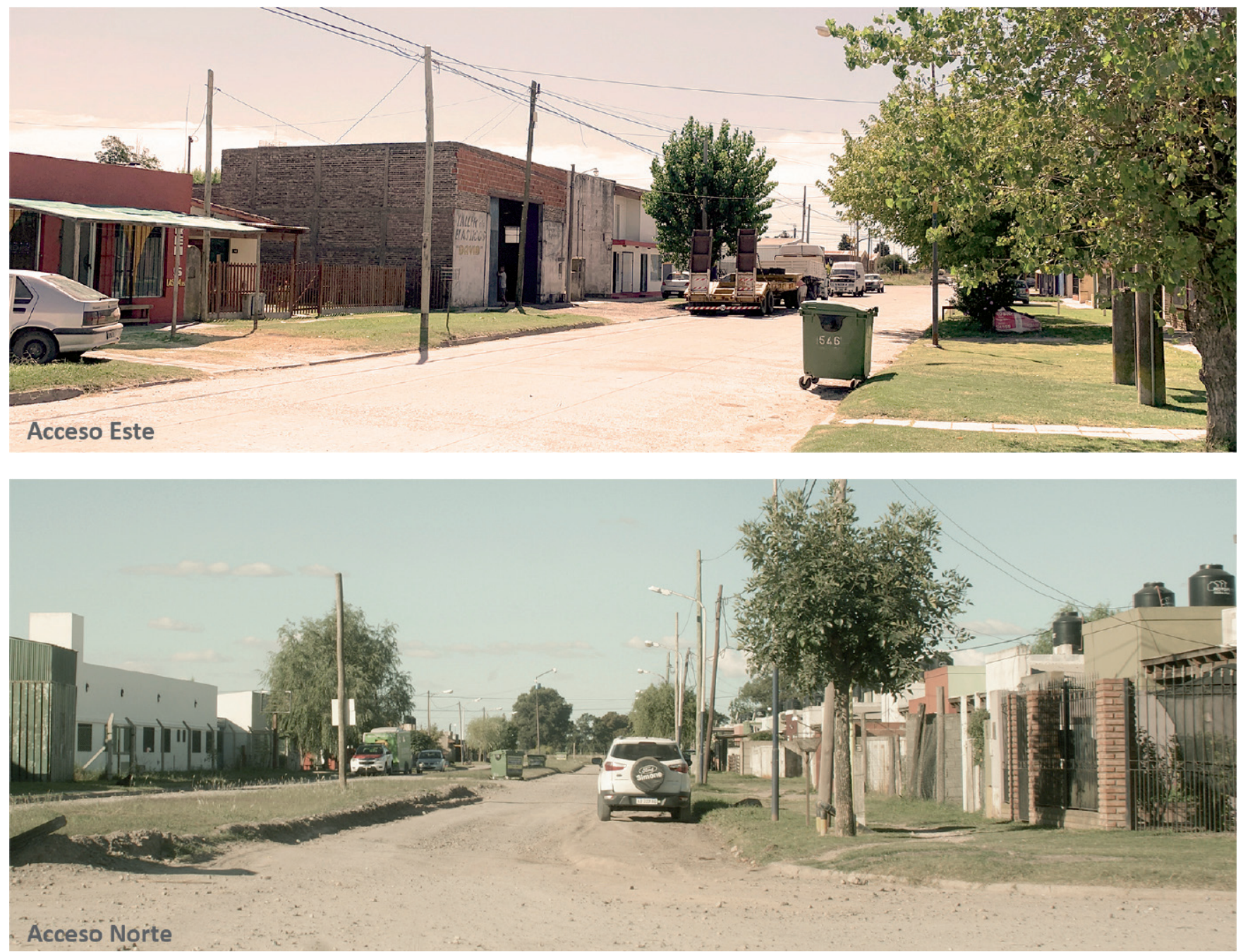

Figura 5. Actual paisaje urbano de los corredores este y norte. Fuente: Giusti, 2021.

A diferencia de los planes de vivienda, en cuyo proceso coincidieron las fases de parcelamiento, urbanización ${ }^{11}$ y edificación; en los loteos populares la fase de parcelamiento fue vertiginosa y por sectores, con una edificación muy tardía (algunos aún sin edificaciones) y un proceso de urbanización que difícilmente pueda ser completado sin grandes inversiones. Promovidos por privados, conformaron una modalidad de ahorro exógena. La totalidad de nuevos parcelamientos no se encontró vinculada a un crecimiento exponencial de su población ni a una necesidad de acceso local a la vivienda. Puede observarse en la tabla 2 que la cantidad de lotes bajo la modalidad de loteo popular asciende a 7.135. Considerando una familia tipo de cuatro integrantes, implicaría una población de 28.540 habitantes, que duplica la existente (tabla 4). Lamentablemente la dinámica expansiva del parcelamiento comprometió una gran cantidad de suelo en el ejido de Chascomús. No fue regulada en su momento, ni fue reformulada por las diferentes experiencias de legislación que se sucedieron hasta la actualidad. El suelo implicado en estos parcelamientos, sometido a la especulación, quedó indefinido, sin uso y desposeído de su condición productiva por muchos años. Fueron, en parte, motivo de la desaparición de prácticas agrícolas para consumo local y son hoy el principal problema de dispersión de la edificación.

11. Debe considerarse que el proceso de urbanización se dio con dificultades ya que: no existió planta de tratamiento cloacal hasta el año 1972; recién en 1974 se extiende la red de agua hacia el corredor norte; y el sistema vial en este sector se realizó a partir de la consolidación de caminos de tierra. 


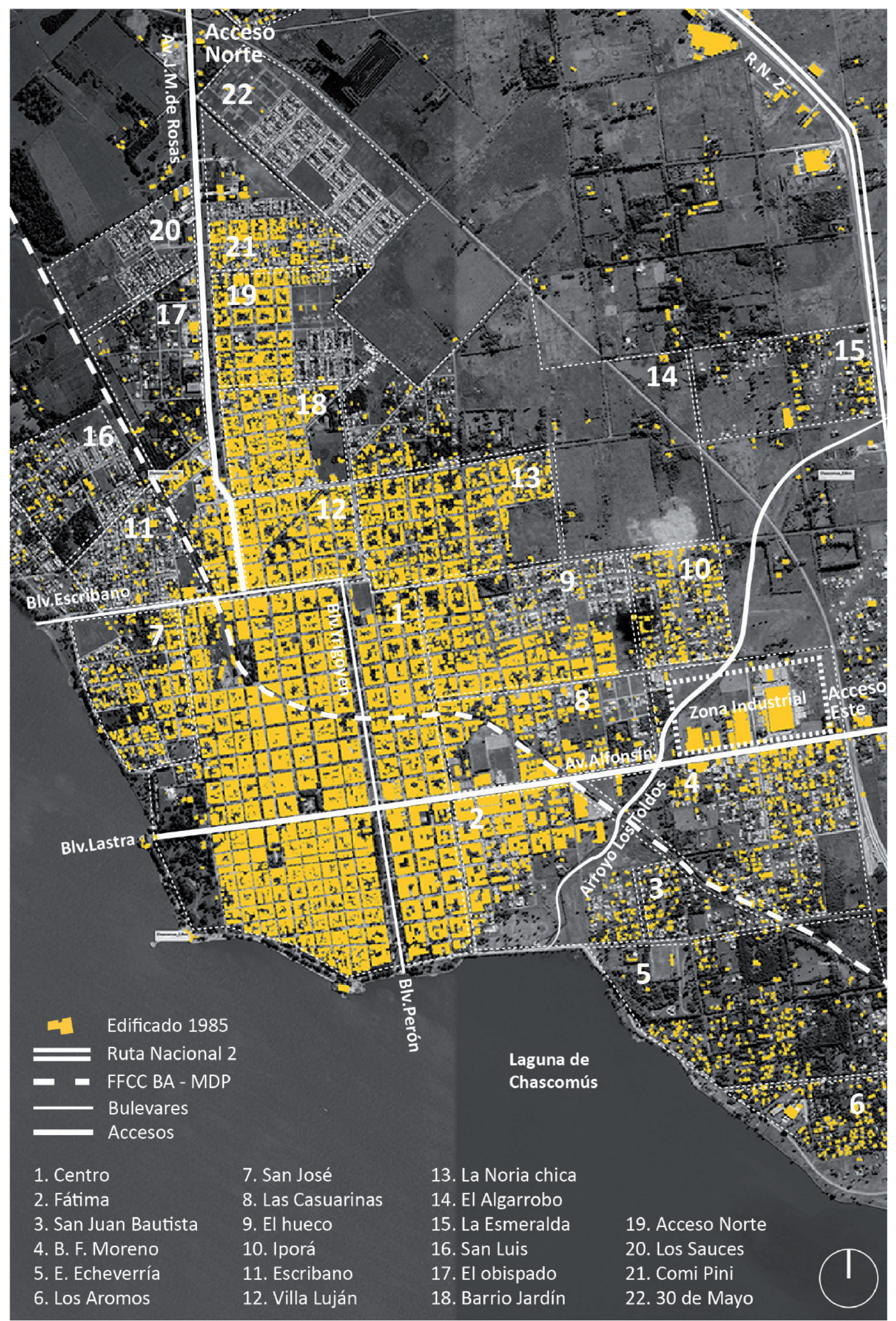

Figura 6. Segunda tendencia de expansión urbana (Barrios, Accesos y vías principales, Arroyos, Ruta Nacional, FFCC ). Fuente: Elaboración propia sobre base satelital de Google 2020. 
Tabla 4. Población urbana de Chascomús (1947-1980).

\begin{tabular}{|c|c|c|c|c|}
\hline Año & Población (hab.) & Variación relativa (\%) & Cantidad de años entre datos & $\begin{array}{c}\text { Tasa de crecimiento medio anual } \\
\text { (C/1000 Hab.) }\end{array}$ \\
\hline 1947 & 21.560 & 32 & 33 & 8,3 \\
\hline 1960 & 24.660 & 14 & 13 & 10,4 \\
\hline 1970 & 25.927 & 5 & 10 & 5,0 \\
\hline 1980 & 29.936 & 15 & 10 & 14,5 \\
\hline
\end{tabular}

Fuente: Giusti, 2021.

\subsection{Extrema dispersión residencial y densificación: créditos de vivienda individual y en cooperativas, reactivación de antiguos loteos populares y barrios parque, urbanizaciones cerradas y edificios multifamiliares (1990-2021).}

El periodo iniciado en la década del noventa y su prolongación hasta la actualidad se caracteriza por un contexto político-económico-social, con reducción de la presencia del Estado en los mecanismos de regulación social, política y económica. Remite a un contexto neoliberal generalizado, con rasgos comunes en la forma de producir el espacio urbano que incentivan las tendencias de expansión desigual en las ciudades. Los agentes privados, al maximizar sus ganancias según una lógica de lucro en desmedro de los costos sociales y ambientales, ordenan e influyen en la vida social de las personas; mientras explotan los elementos ambientales presentes en los territorios. Tal lógica, opuesta a cualquier intento de bienestar y optimización de los recursos (humanos y ambientales), termina por profundizar la exclusión, la segregación social y el riesgo ambiental. En los pueblos del interior, cuyos recursos económicos y humanos son muy limitados, la situación se agrava aún más. Particularmente en Chascomús también se agudiza frente al carácter permisivo de las normativas, de carácter sectorial, limitadas a lo urbano y desprovistas de una visión territorial integral como el Plan Regulador de 1981 (PR) y Plan de Desarrollo Territorial de 2014 (PDT) ${ }^{12}$. Mientras la extrema dispersión del edificado comienza en la década del noventa incrementándose hacia la actualidad, los procesos de densificación se inician en 2014 al convalidarse el PDT.

Cabe destacar que el proceso de extrema dispersión y densificación que sintetizamos a continuación se da a pesar de existir estabilidad en la dinámica poblacional de la ciudad de Chascomús (tabla 5), la cual presenta a su vez procesos de decrecimiento poblacional en las áreas centrales de mayor consolidación urbana. Esto se explica bajo la existencia de dinámicas de especulación inmobiliaria derivadas de la actividad turística y de la valorización ambiental y paisajística de la ciudad, con consecuencias irreversibles para la planificación territorial.

A partir de 2004, con el repunte de la economía luego de la crisis económica, social y política que atravesó la Argentina en 2001, se presentan en simultáneo diversas estrategias de expansión urbana desplegadas tanto por el sector privado como público. Se mantienen aquellas ya existentes: subdivisiones en el centro consolidado, reformas de viviendas antiguas para complejos o departamentos turísticos, y edificación en loteos populares extraurbanos en áreas complementarias, distantes al centro consolidado. A dichas estrategias se adiciona el modelo de urbanización cerrada en sus tipologías de mayor impacto territorial (Club de campo y Club de chacra) localizadas en terrenos complementarios y rurales (tabla 6). También se suman, a partir del inminente cambio de normativa ${ }^{13}$, nuevos procesos especulativos sobre terrenos que son quitados del mercado aguardando una mayor rentabilidad ante el cambio de indicadores urbanísticos.

12. Entre los años 2005-2007 se elaboró el Plan Estratégico Chascomús (PECH) del que derivaron dos documentos: Diagnóstico y Propuestas. La riqueza del Plan se centró en el uso de técnicas participativas de legitimación a partir del trabajo diagnóstico en talleres con los diferentes actores; que sin embargo no tuvieron continuidad en las etapas posteriores de elaboración de políticas, proyectos o propuestas como el Plan de Desarrollo Territorial de 2014.

13. El PDT fue aprobado por el ejecutivo municipal en 2009 pero no fue convalidado por la Provincia de Buenos Aires hasta el año 2014. 
Tabla 5. Población urbana de Chascomús (1980 a 2010).

\begin{tabular}{|c|c|c|c|c|}
\hline Año & Población (hab.) & Variación relativa (\%) & $\begin{array}{l}\text { Cantidad de años entre } \\
\text { datos }\end{array}$ & $\begin{array}{c}\text { Tasa de crecimiento medio } \\
\text { anual (C/1000 Hab.) }\end{array}$ \\
\hline 1991 & 35.174 & 17 & 11 & 14,8 \\
\hline 2001 & 38.647 & 10 & 10 & 9,5 \\
\hline 2010 & 42.277 & 9 & 9 & 10,0 \\
\hline
\end{tabular}

Fuente: Giusti, 2021.

Tabla 6. Urbanizaciones cerradas 1978-2008.

\begin{tabular}{|c|c|c|c|c|}
\hline Año & Cantidad de lotes & Referencias y Localización & Ha. & Barrio actual \\
\hline 1978 & 590 & $\begin{array}{l}\text { Golf Club Chascomús (barrio cerrado) Acceso Nor- } \\
\text { te Juan M. de Rosas y Ruta Provincial } 20\end{array}$ & 60 & Country \\
\hline 1999 & 138 & $\begin{array}{l}\text { Barrio de Chacras Laguna Vitel (Club de chacras) } \\
\text { Frente a las costas de la Laguna Vitel y Ruta Pro- } \\
\text { vincial } 20\end{array}$ & 320 & Zona Rural \\
\hline 2006 & 350 & $\begin{array}{l}\text { Club de Campo Puerto Chascomús (club de cam- } \\
\text { po) Camino de circunvalación Laguna de Chasco- } \\
\text { mús. Frente a la Laguna }\end{array}$ & 300 & $\begin{array}{l}\text { Zona complementaria } \\
\text { Franja de protección del } \\
\text { paisaje Natural }\end{array}$ \\
\hline 2008 & SD & Lomas de Chascomús (club de campo) & 40 & Zona complementaria \\
\hline- & 1078 & - & 720 & - \\
\hline
\end{tabular}

Fuente: Giusti, 2021.

La edificación en las zonas periféricas, a pesar de la existencia de una gran cantidad de lotes vacíos en las áreas urbanas provistas de infraestructuras básicas -o al menos más cercanas a estas-, pone en riesgo la capacidad y posibilidad de que el municipio logre en algún momento proveer de servicios básicos a estas poblaciones. El PR estipula para el área urbana una población de 100.000 habitantes. Sin embargo, la edificación se localiza de forma expansiva y dispersa en áreas complementarias (figura 7), sin las condiciones mínimas de saneamiento hidráulico, equipamiento social e infraestructuras. Existe por lo tanto un desfasaje entre las áreas mejor provistas de la ciudad y la localización efectiva de la población. En el período 1980-1991 el área central (que incluye al plan Arrufó más el sector oeste de los barrios El Hueco y Fátima) creció un 7,5 \%, mientras que el resto, un 38\% (Tauber, 1994, p.24). Esto puede explicarse, en parte, debido al incremento del valor del suelo en el área central, pero también por la ausencia de políticas que absorban las demandas de vivienda en los sectores más consolidados. A ello se suma una ausencia de límites a los loteos periféricos en suelos no aptos por no disponer de las condiciones de equipamiento, servicios e infraestructuras propias del espacio urbano.

La aparición en este período del Estado Nacional con nuevos créditos para financiamiento en la adquisición de terrenos y construcción de vivienda individual y en cooperativas (tabla 7), dinamizó el mercado inmobiliario y reactivó la economía asociada a la construcción para sectores medios relegados. No obstante, también profundizó el modelo de ocupación en los barrios periféricos o en áreas complementarias, y sin infraestructuras urbanas básicas ni servicios. Los grupos sociales de menores recursos se localizaron en el eje este: barrios El Porteño, Los Eucaliptus, Fátima, Obrero, Iporá y Algarrobo; mientras que los sectores medios lo hicieron completando lotes vacantes en el tejido más consolidado o estableciendo un nuevo eje de crecimiento en el sector oeste de la ciudad -en torno a la vía paralela a la costanera de la laguna, sobre la calle Orzali (véase figura 10). Este nuevo eje se estableció a partir de la subdivisión de chacras cercanas a la laguna, adquiridas por familias que habitaban el centro y que liberaron sus viviendas para alquiler o usos vinculados a actividades turísticas. 
Por su parte, el crecimiento natural sin ayuda de créditos también reactiva los loteos extraurbanos. Por un lado, las clases de menor nivel socio-económico se localizan en zonas de conflicto socio-ambiental (cercanía a arroyos, zonas inundables, entre otros), en cercanía a la Autovía № 2 (Barrios El Porteño", "San Nicolás", "San Cayetano" y "El trébol"), o en zonas donde por existir indefinición dominial la tierra podía ser adquirida bajo modalidades de "usucapión" (prescripción adquisitiva). Por otro, las clases medias edifican principalmente en loteos extraurbanos abiertos (barrios parque), vinculados de forma directa con la Laguna de Chascomús ya sea para vivienda permanente o como segunda residencia (Barrio La Liberatta, Barrio Parque Girado y Barrio Lomas Altas) (figura 8).

En síntesis, la extrema dispersión del edificado se presenta entonces con un doble perfil de habitante que, aunque con diferenciación en la modalidad físico-espacial de la expansión, termina produciendo un mismo impacto en el territorio y en los bienes sociales: elevado consumo de suelo de valor ambiental y cultural; fuerte presión sobre el paisaje y el ambiente; pérdida de terrenos de alto valor productivo; y una acentuación de la fragmentación y segregación urbana. Por su parte, las clases medias y altas locales y muchos propietarios de segundas residencias buscan, bajo diversas tipologías, localizarse en áreas de valor paisajístico y ambiental, o con ciertas condiciones de exclusividad.

Mientras el modelo de la urbanización cerrada representa el modelo de una sociedad no reconciliada, también pone en evidencia la voluntad de algunos sectores de poseer aquello que es valorado. Este proceso puede entenderse a partir de la Naturbanización (Prados, 2009; Prados \& Giusti, 2010; Giusti \& Prados, 2013) que explica cómo el valor del paisaje y la naturaleza son entendidos como activos residenciales, aunque al mismo tiempo y contradictoriamente se los degrada. Además del gran impacto territorial derivado del tamaño de los loteos ${ }^{14}$, en ellos se producen nuevas naturalezas escénicas y la privatización de bienes comunes como las costas y el agua, que pasan de ser bien común a ser mercantilizados a partir de su uso restringido ${ }^{15}$ (Giusti et al., 2020). La acumulación por desposesión a la que refiere Harvey (2004) se presenta en el caso de Chascomús con todas las contradicciones ambientales y sociales propias de las prácticas del urbanismo neoliberal. La ciudad y su laguna son promocionadas a partir de nuevas representaciones construidas en torno a la naturaleza avaladas en los instrumentos normativos, lo que favorece su mercantilización y necesidad de consumo, mientras se las despoja de su condición de bien común y de su capacidad de brindar y potenciar servicios ecológicos fundamentales para la vida.

Otra oportunidad perdida no recogida en el PDT fue el corrimiento de la traza del Ferrocarril en 2009. La nueva traza desplazada hacia el norte constituía la posibilidad de determinar un límite a la expansión residencial (límite que no se volvió a conformar desde el Plan de 1855), y como bien plantea Tauber (1994), un dato para definir el tamaño y la forma de la ciudad. A su vez, en términos de movilidad y accesibilidad, la ausencia de una propuesta de transporte público en una ciudad donde existe un excesivo uso del automóvil privado, del remise ${ }^{16}$ y las motocicletas para los movimientos internos de su población, son rasgos heredados que no son abordados y que agravan el contraste y la segregación social.

La última modalidad en efectivizarse fue la de densificación (figura 9), que tras la aprobación del PDT en 2014 comienza a evidenciarse lote por lote en torno a las principales arterias de la estructura vial (figura 9). Ese modelo de densificación, propio de los centros urbanos de mayor jerarquía, impacta fuertemente en las cualidades distintivas del paisaje cultural de Chascomús. Si bien la densidad es concebida como una modalidad necesaria ante la necesidad de acceso a la vivienda en zonas de consolidación urbana, bajo estas características morfológicas y sin políticas de control del valor del suelo o de acceso a la vivienda, impactan en el patrimonio urbano y promueven procesos de dispersión; mientras que finalmente son aprovechadas por sectores de mayor poder adquisitivo como estrategia de inversión o segunda residencia.

14. La Urbanización cerrada "Puerto Chascomús" supera en tamaño al plano de Arrufo de 1855 que llevó más de un siglo en completarse.

15. El Club de Chacras Laguna Vitel restringe el acceso público a la costa al no existir un sector de costa pública entre el loteo y el recurso lagunar, mientras que en Puerto Chascomús la laguna artificial principal al interior del emprendimiento conecta sus aguas con la Laguna de Chascomús a partir de un canal navegable.

16. Automóvil con chofer, cuyo servicio, efectuado por horas o kilómetros de recorrido, se contrata en una agencia. 

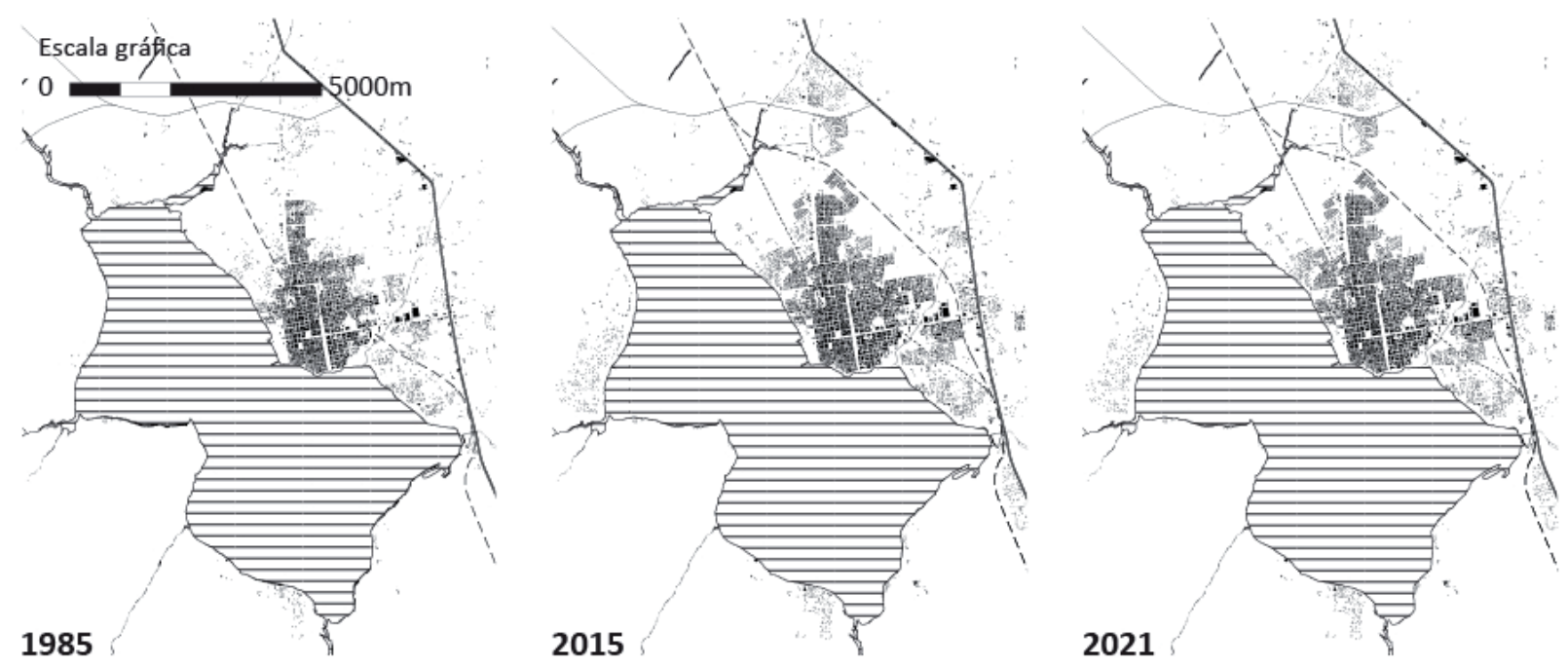

Escala gráfica
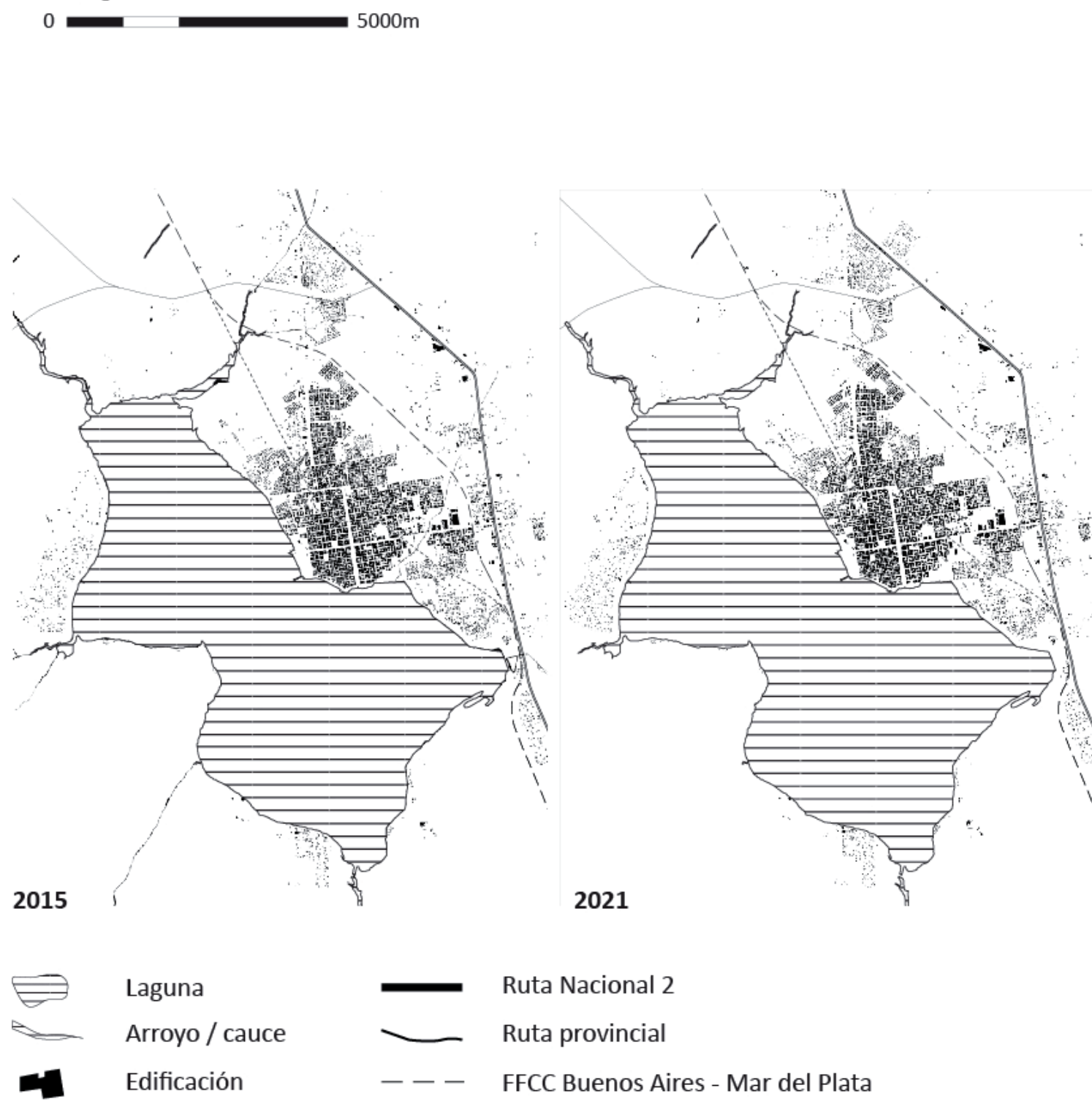

Figura 7. Extrema dispersión y densificación (1990-2021). Fuente: Giusti, 2021. 
Tabla 7. Intervenciones de vivienda financiadas por el Estado entre 1990 y 2015.

\begin{tabular}{|c|c|c|c|c|}
\hline Año & Cantidad de Viviendas & Identificación/ Plan & Barrio & Zona \\
\hline 1990 & 50 & Plan de Viviendas Progresivas & San Luis & Noroeste \\
\hline \multirow{2}{*}{1991} & 85 & Instituto de Viviendas. PBA & Comi-Pini & Norte \\
\hline & 12 & PAMI & Escribano & Noroeste \\
\hline 1992 & 21 & Instituto de Viviendas. PBA & El Hueco e Iporá & Este \\
\hline \multirow{2}{*}{1994} & 9 & Reciclaje & San Luis & Noroeste \\
\hline & 10 & FOPROVI & El Porteño & Este \\
\hline 1995 & 15 & PROCASA 3 & San Luis & Noroeste \\
\hline 1997 & 8 & Solidaridad 2 & San Luis & Noroeste \\
\hline 2003 & 8 & Solidaridad & San Luis & Noroeste \\
\hline 2007 & $\begin{array}{l}500 \\
100\end{array}$ & Plan Federal & $\begin{array}{l}30 \text { de Mayo } \\
\text { San Luis }\end{array}$ & Norte \\
\hline \multirow[t]{2}{*}{$\begin{array}{l}2014 \\
2015\end{array}$} & 257 & $\begin{array}{l}\text { Créditos a través de bancos (Pro- } \\
\text { crear y otros) }\end{array}$ & $\begin{array}{l}\text { Múltiples sectores del area urba- } \\
\text { na y complementaria }\end{array}$ & - \\
\hline & 1075 & - & - & - \\
\hline
\end{tabular}

Fuente: Giusti, 2021.
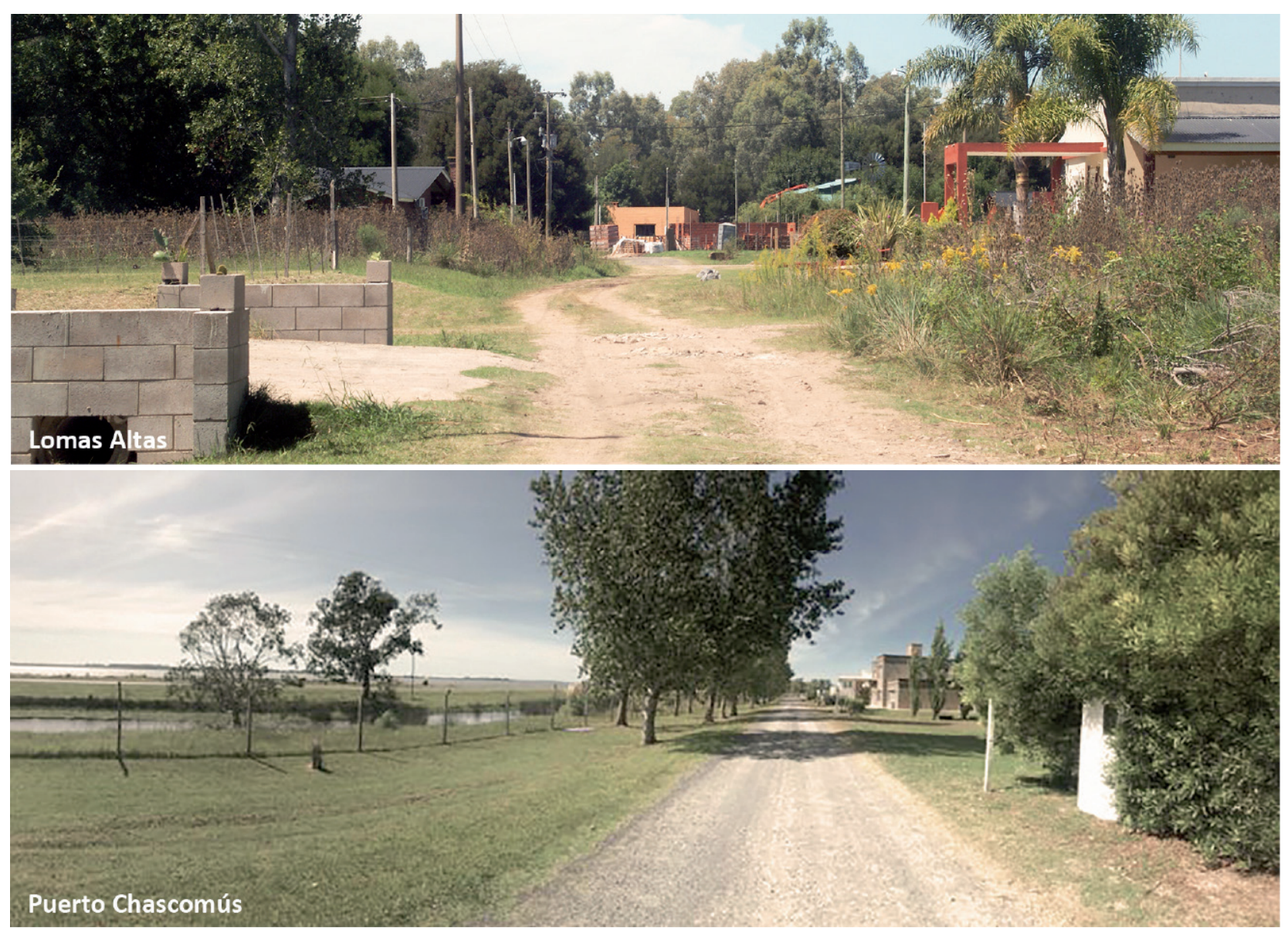

Figura 8. Paisaje barrio extraurbano abierto y cerrado. Fuente: Giusti, 2021. 
En paralelo, en el ámbito rural del partido, la demanda internacional de cereales y oleaginosas que inicia en la década del noventa desplaza otras actividades productivas, proceso denominado agriculturización. El principal estandarte de dicho proceso a nivel nacional fue la soja (transgénica y con uso de agroquímicos) la cual en Chascomús ha ido desplazando la actividad ganadera (históricamente la principal actividad productiva de la Cuenca Deprimida del Salado) hacia suelos de menor potencial productivo. A su vez, el excedente económico de los productores locales "sojeros" es transferido al sector inmobiliario alimentando los procesos de especulación, principalmente de aquellos que alquilan sus campos a pools de siembra para plantaciones de soja. La dupla agriculturización abierta y urbanización cerrada ha conformado territorios estrangulados (Giusti \& Prividera, 2015), de impacto en la desaparición y afectación de patrimonio natural y cultural en zonas más despobladas. Cabe destacar que el avance de las fronteras de la explotación agraria sojera no sólo ha incrementado la actual competencia sobre los usos del suelo, sino que también tiene efectos negativos en el medio ambiente, la biodiversidad y los ecosistemas, en la calidad y precios de los alimentos y la salud de las personas.

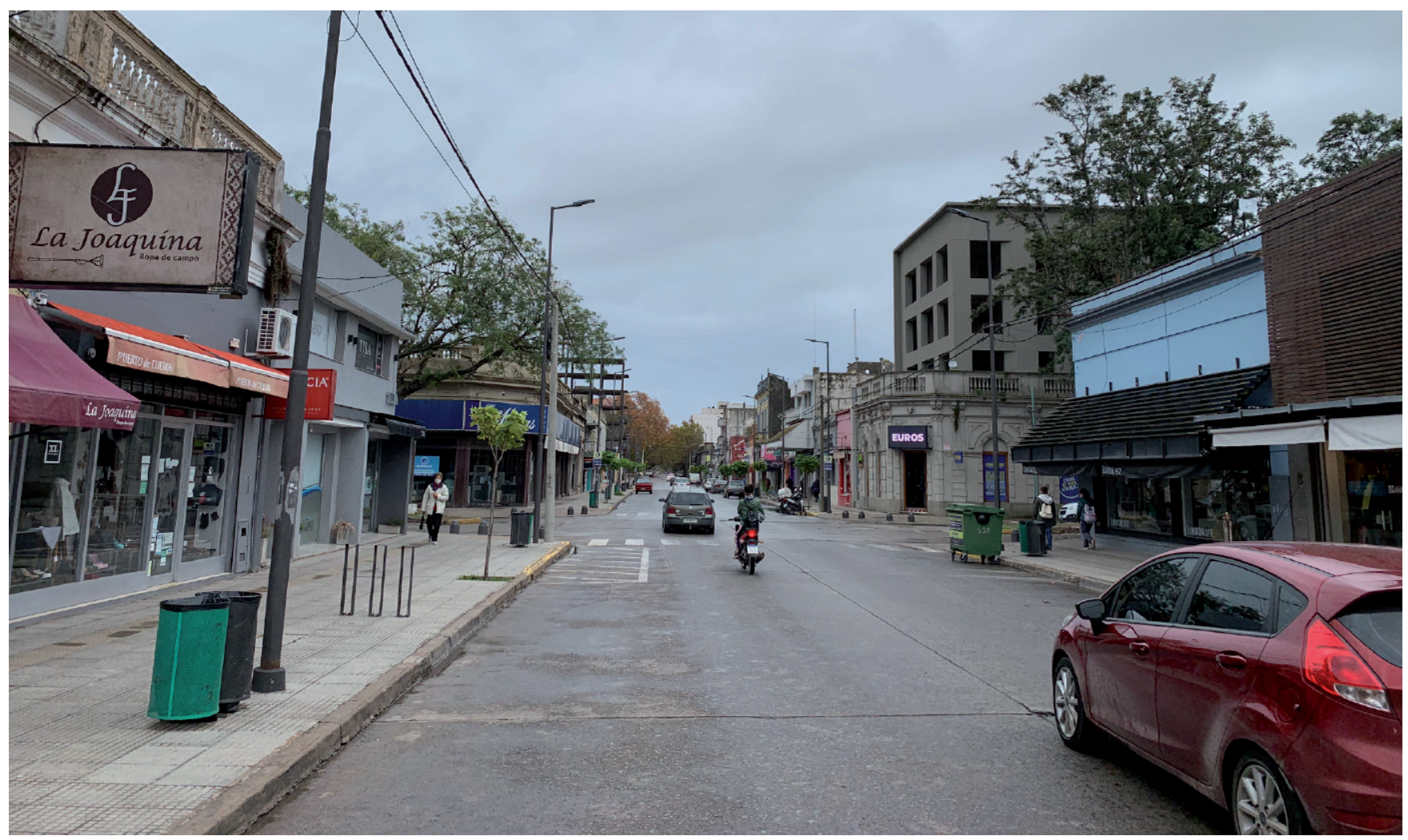

Figura 9. Paisaje urbano de la densificación: verticalización lote por lote en torno a arterias principales. Fuente: Autoras.

\section{CONCLUSIONES}

El artículo propuso una mirada a Chascomús partiendo de reconocer su condición de ciudad intermedia, su rol estratégico y su valor patrimonial en términos ambientales y culturales. El recorrido histórico esbozado, integrando las dimensiones políticas, económicas y a la vez morfológicas, permitió identificar diferentes patrones de crecimiento urbano. Esto habilitó a complejizar la mirada sobre qué relaciones se establecieron y establecen entre el medio urbano, el medio rural y el medio natural en la conformación y transformación socio-espacial de la ciudad y su territorio. En un segundo orden de ideas, permitió identificar aquellas dinámicas de crecimiento latinoamericano, las propias a las ciudades intermedias, y las específicas al caso de estudio. 


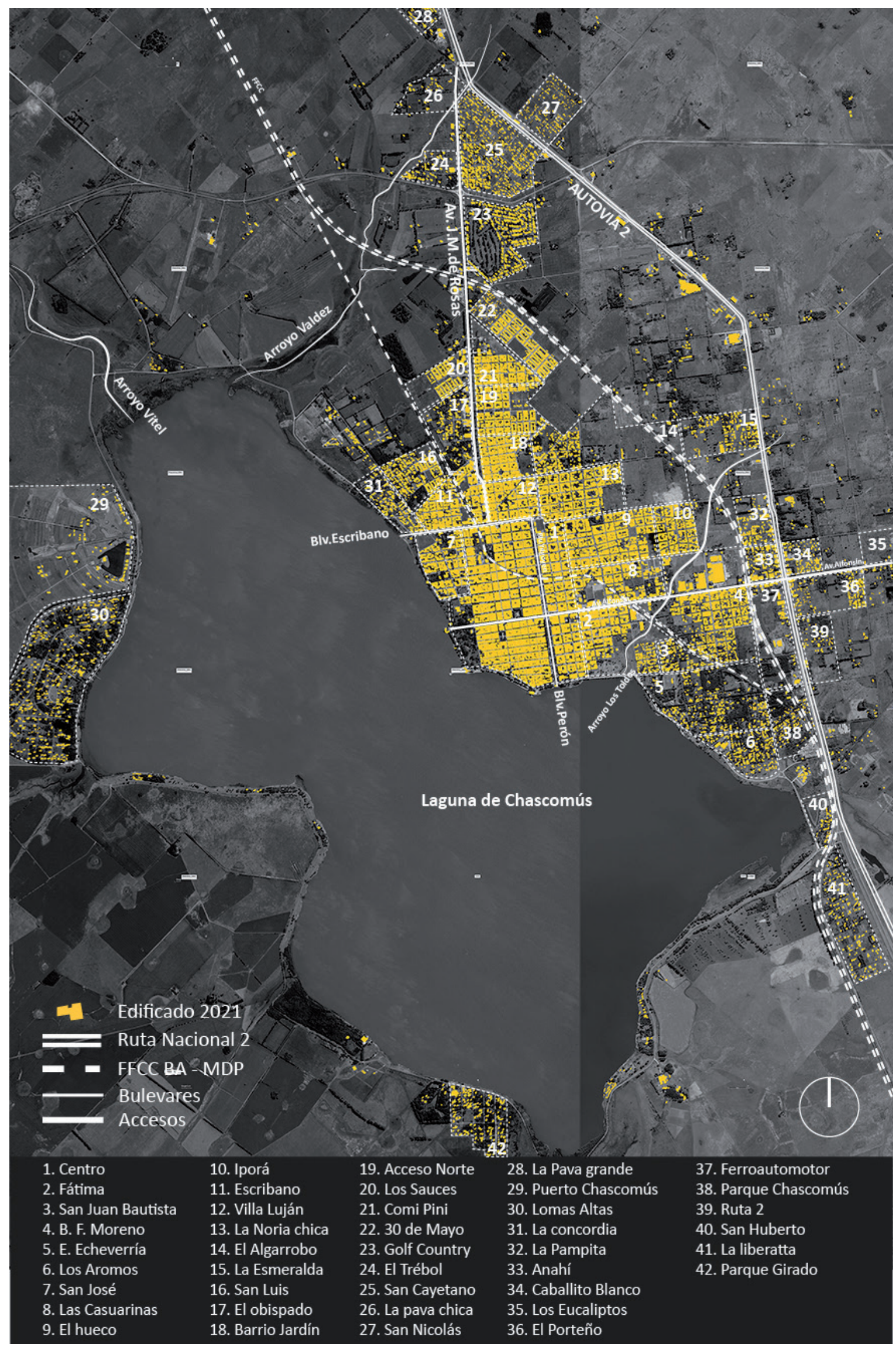

Figura 10. Tercera tendencia de expansión urbana (Barrios, Accesos y vías principales, Arroyos, Rutas, FFCC). Fuente: Elaboración propia sobre base satelital de Google 2021. 
En primera instancia el estudio puso en evidencia que, más allá de los contextos macro-económicos y modelos de acumulación vigentes, los principales motores de cambios en las dinámicas surgen de elementos de la propia historia de la ciudad. Las temporalidades delimitadas se corresponden con un tipo de explotación territorial predominante, pero al interior de éstas también se reconocen condiciones específicas: -especialmente- su condición lagunar, la incidencia del ferrocarril y la pavimentación de la Autopista $\mathrm{N}^{\circ} 2$. Ello permite dar cuenta de una ciudad, que, si bien, observa una dinámica de crecimiento similar a las ciudades latinoamericanas medianas, también evidencia una trayectoria particular. Por ejemplo, la actividad turística -estimulada por el incremento del uso del automóvil particular-fue, desde los comienzos un elemento dinamizador de los cambios morfológicos de la ciudad.

Profundizando la mirada, cabe reflexionar en torno a la relación de las dinámicas de crecimiento de la Ciudad y su planificación y el registro de las condiciones ambientales locales, es decir, la racionalidad urbano-ambiental. El momento inicial de Completamiento y Compactación (1826-1945) efectivamente siguió los lineamientos esbozados en los primeros Planes a lo largo de noventa años. Registra las mayores tasas de crecimiento poblacional (llegando a superar el 50 \% en algunos años), concentradas en una superficie acotada con gran provisión de espacios verdes públicos y una relación con la laguna según el paradigma propio del período, de carácter ingenieril y de fuerte impacto. Para entonces, los procesos que se dieron respondieron al afianzamiento del modelo agroexportador; $y$ tanto el territorio como sus ecosistemas naturales fueron profundamente alterados, a partir de las actividades agrícolas extensivas.

Contrariamente, el período de Ensanche y dispersión de la matriz edificada (1946-1989) refleja una dinámica de crecimiento espontánea, urgida por la necesidad de una ciudad que tardíamente se desarrollaba en términos industriales y requería de mano de obra; seguido de un esfuerzo por regularizar y ordenar normativamente un acto ya consumado. En este período, no obstante, se advierte una desaceleración del crecimiento poblacional registrado anteriormente y un crecimiento urbano expandido, motorizado por los loteos populares implicando una gran cantidad de suelo de valor productivo para el consumo local. Una vez más, los cambios sobre el perfil productivo del territorio propician nuevas dinámicas de poblamiento que terminan por alentar un crecimiento poco eficiente y desregulado de la mancha urbana; conformando uno de los aspectos característicos de la urbanización latinoamericana, observable tanto en grandes centros como en ciudades medias.

Por último, el período actual (1990-2021) se caracteriza por tendencias contrapuestas de extrema dispersión residencial y densificación que expresan la forma urbana del modelo de acumulación neoliberal, pero que son también legado de las dinámicas anteriores. Los antecedentes de estudio junto con los hallazgos alcanzados, demuestran que es un rasgo característico de los contextos metropolitanos y, también, -con diferencias- de las ciudades de escala intermedia. Chascomús observa tardíamente los efectos de las iniciativas de loteos populares que, por un lado, en las grandes ciudades metropolitanas se dieron en décadas pasadas y bajo diferentes arreglos institucionales -como los gobiernos de orientación popular-. Por el otro, mientras que éstas fueron el medio de acceso a la vivienda de los sectores populares; en Chascomús también han sido, dependiendo su localización, oportunidad para la edificación de segundas residencias. A pesar de que se mantuvieron inertes por muchos años, los nuevos marcos normativos no visualizaron dicha problemática que podría, al menos, haber sido mitigada con nuevos instrumentos o políticas de planificación. En adición a la pérdida de suelo productivo para consumo local se presenta la pérdida de suelo de alto valor paisajístico y ambiental.

Rastrear el pasado, sus huellas y dinámicas nos permite comprender con mayor cabalidad los desequilibrios que enfrenta la ciudad hoy y nos aporta nuevas herramientas para avanzar en su problematización. La dinámica retratada constata las contradicciones socio-ambientales en las políticas públicas para el ordenamiento territorial. El recorrido histórico pone en evidencia la progresiva desregulación por parte del Estado de las pautas de crecimiento de la ciudad, que se traduce en un avance del desarrollo urbano sobre espacios desprovistos de infraestructuras básicas o en conflicto ambiental. La edificación en las zonas periféricas, pese a la existencia de una gran cantidad de lotes vacíos en las áreas urbanas dotadas de infraestructuras básicas -o al menos más cercanas a estas-, pone en riesgo la capacidad y posibilidad de que el municipio logre en algún momento proveer de servicios básicos a estas poblaciones. Asimismo, el estudio de la forma implícita en los instrumentos de planificación devela la ausencia de un modelo de ciudad rector, a la vez que 
se constata un bajo nivel asignado a la dimensión ambiental y una indefinición en relación a la escala de ciudad proyectada que debe ser atendida. Con ello, las preguntas formuladas al inicio a razón de las nuevas tendencias de poblamiento, no parecieran lograr respuestas alentadoras sobre la factibilidad de un crecimiento urbano equilibrado y sostenible.

Finalmente, el estudio de la evolución de Chascomús, procuró asimismo aportar- con base empírica en una ciudad media que no forma parte de ningún sistema urbano metropolitano- a los cuestionamientos actuales que desde la planificación y el ordenamiento se reavivan en relación a la primacía urbana y la estructura macrocefálica del territorio nacional. La descripción diacrónica y a la vez sincrónica de la ciudad advierte sobre el carácter estructural y multidimensional de este problema, que no sólo se corresponde con las deficiencias del urbanismo en los grandes centros urbanos, sino también con la ausencia de esquemas y lineamientos propios para pensar el crecimiento de las áreas menores. La desarticulación observada entre el nivel nacional, provincial y municipal en el caso chascomunense ilustra un recorrido semejante al de otras ciudades intermedias. Frente a ello, la reciente llegada de población nueva a las ciudades intermedias amerita ser también analizada en consonancia con el sistema de asentamientos urbanos que compone el país.

\section{Declaración responsable y conflicto de intereses}

Las autoras declaran que no existe ningún conflicto de interés en relación con la publicación de este artículo. Las contribuciones y tareas llevadas a cabo para la elaboración del presente trabajo, si bien fueron discutidas, redactadas, revisadas y editadas por ambas autoras, se han distribuido de la siguiente manera: La autora 1 se concentró en la conceptualización, resumen, metodología, datos, gráficos y mapas, resultados y revisión bibliográfica, mientras que la autora 2 se concentró en la conceptualización, introducción, marco teórico, metodología, conclusiones y revisión bibliográfica.

\section{REFERENCIAS}

Aliata, F. (2006). La ciudad regular. Arquitectura, programas e instituciones en el Buenos Aires posrevolucionario (1821-1835). Prometeo UNQ.

Aliata, F. (2010). Transformaciones en el hábitat rural. Los planos topográficos de Chascomús, 1826-1854. Mundo Agrario 10 (20), 1-34. http://www.redalyc.org/articulo.oa?id=84514811010

Aliata, F. (2010b). Las raíces del árbol de la libertad. El legado ilustrado en la fundación de pueblos en la pampa bonaerense durante el siglo XIX. Nuevo Mundo Mundos Nuevos. https://doi.org/10.4000/nuevomundo.59222

Bähr, J. \& Borsdorf, A. (2005). La ciudad latinoamericana. La construcción de un modelo. Vigencia y perspectivas. Ur[b] es Revista de ciudad, urbanismo y paisaje, 2(2), 207-222. https://www.uibk.ac.at/geographie/personal/borsdorf/pdfs/ urbes-2-2005-207-221.pdf

Borsdorf, A. (2003). Cómo modelar el desarrollo y la dinámica de la ciudad latinoamericana. EURE, 29 (86), 7-49. https:// doi.org/10.4067/S0250-71612003008600002

Cabodi, J.J. (1950). Historia de la ciudad de Rojas hasta 1784, el fuerte de la horqueta de Rojas (1777-79), la guardia de Rojas (1779). En Serie Contribución a la historia de los pueblos de la Provincia de Buenos Aires. № 27. Archivo Histórico de la PBA.

Capel, H. (2002). La morfología de las ciudades. Tomo 1. Sociedad, cultura y paisaje urbano. Ediciones del Serbal.

Corboz, A. (2004). El territorio como palimpsesto. En A. Ramos (ed.), Lo urbano en 20 autores contemporáneos (pp. 25-35). UPC. https://bibliodarq.files.wordpress.com/2014/09/ramos-a-m-lo-urbano-en-20-autores-contemporc3a1 neos.pdf De Paula, A. J. (2000). Las nuevas poblaciones en Andalucía, California y el Río de La Plata, 1767-1810. IAA-UBA.

De Paula, A. J. (2004). La urbanística hispanoamericana y el Río de la Plata. Geodemos, 7/8, 95-138. http://www.imhicihu-conicet.gob.ar/html/Publ_Period/Geodemos\%207-8.pdf

De Laurentis, F. A. (2014). Destino: el mar. La pavimentación de la ruta a Mar del Plata y su impacto en la transformación del turismo nacional. Épocas, 10, 101-114. https://p3.usal.edu.ar/index.php/epocas/article/view/3047

Giusti, M. (2021). Elogio del espacio libre. Racionalidad ecológica vs. urbanización: Las formas de la expansión urbana y de los espacios libres en pequeñas ciudades del interior bonaerense. Una nueva perspectiva de análisis. El caso de Chascomús, 
Provincia de Buenos Aires, Argentina (1779-2020). [Tesis Doctoral cotutelada, Universidad de Sevilla y Universidad de Buenos Aires]. Repositorio Institucional US. https://idus.us.es/handle/11441/109161

Giusti M., La Valle G. \& Nieva A. (2020, mayo - octubre). La laguna de Chascomús en cinco tiempos. Confluencias y disputas entre paisaje, ambiente y urbanización. AREA, 26(2), 1-17. https://area.fadu.uba.ar/wp-content/uploads/ AREA2602/2602_giusti_et_al.pdf

Giusti, M. \& Prividera, G. (2015). Urbanización cerrada, agriculturización abierta. La Región Metropolitana de la Ciudad de Buenos Aires. En S. Vidal- Koppmann (comp.). Metrópolis en mutación (pp. 153-178). Café de las ciudades.

Giusti, M. \& Prados, M.J. (2013). Naturbanización en la Pampa Argentina. Urbanización vs Racionalidad ecológica. El caso de Chascomús (Provincia de Buenos Aires, Argentina). Actas del V Seminario Internacional de Investigación en Urbanismo, Barcelona- Buenos Aires (pp. 619-635). http://hdl.handle.net/2099/14474

Gómez Pintus, M.H. (2013). Las formas de expansión. 1910-1950: barrios parques y loteos de fin de semana en la construcción del espacio metropolitano de Buenos Aires. [Tesis Doctoral Universidad Nacional de La Plata]. Repositorio Institucional FAU-UNLAP. http://bdzalba.fau.unlp.edu.ar/greenstone/collect/postgrad/index/assoc/TE18.dir/doc.pdf

Harvey, D. (2004). The “New” Imperialism: Accumulation by Dispossession. Socialist Register, (40), 63-87. https://socialistregister.com/index.php/srv/article/view/5811

Levene, R. (Dir.) (2008). Historia de la Provincia de Buenos Aires y formación de sus pueblos (2 tomos). Archivo Histórico de la Provincia de Buenos Aires. Reedición digital. [Documento original de 1941].

Mertins, G. (2000). Ciudades medianas en América Latina: criterios, indicadores y el intento de un modelo de su diferenciación socio-espacial y funcional. Boletín de Estudios Geográficos, 96, 139-148. https://bdigital.uncu.edu.ar/10028

Morosi, J., Vitalone, C. \& Amarilla, B. (1991). La cuadrícula en las ciudades bonaerenses. Aspectos morfológicos, ambientales y económicos. LINTA-CIC.

Pesoa Marcilla, M. (2012). Cien Ciudades para la Pampa. Idea, técnica y construcción de la forma urbana en nuevas ciudades del siglo XIX de la provincia de Buenos Aires. Revista Iberoamericana de Urbanismo 7, 3-17. https://www.raco. cat/index.php/RIURB/article/view/267918

Pesoa Marcilla, M. (2016). Una ciudad para la pampa: la construcción del territorio en la Provincia de Buenos Aires (1810-1916). [Tesis Doctoral, Universitat Politécnica de Catalunya]. Repositorio Institucional. http://hdl.handle.net/10803/386476

Politis, G. (2012). Las poblaciones prehispánicas. En H. Otero (Dir.), Historia de la provincia de Buenos Aires. Tomo 1: población, ambiente y territorio (pp. 211-248). Edhasa.

Prados, M.J. (2009). Naturbanization, new identities and processes for rural-natural areas. Taylor \& Francis

Prados, M.J. \& Giusti, M. (2010). Naturaleza y Espacio Construido. Un Análisis exploratorio de la Naturbanización en Andalucía. Espacios y Paisajes Urbanos: reflexionar sobre su presente para proyectar su futuro. Coloquio de Geografía Urbana, 1, 1-17. Universidad de Oviedo. http://hdl.handle.net/11441/26663

Randle, P. (1977) La ciudad pampeana. Geografía histórica-geografía urbana. Oikos.

Randle, P., Francini, G, Sassone, S., De Nistal, M.A.I. \& Vidal, S. (1992). Ciudades intermedias. Su reactivación en la región pampeana. Fundación Banco de Boston.

Randle, P. \& Guerevitz, N. (1971). Atlas Geografía Histórica de la Pampa Anterior. Eudeba.

Razori, A. (1945). Historia de la ciudad argentina. 3 Tomos. Imprenta López.

Santos, M. (2009). Espacio y Método. Algunas reflexiones sobre el concepto de espacio. Gestión y Ambiente, 12(1), 147148. https://www.redalyc.org/pdf/1694/169414454011.pdf

Sassone, S. (1998). Reestructuración territorial y ciudades intermedias en Argentina. Signos Universitarios 18 (34), 15-70. https://p3.usal.edu.ar/index.php/signos/article/view/2314

Soja, E. (2000). Postmetropolis: critical studies of cities and regions. Blackwell Publishing.

Solà Morales, M. (1997). Las formas del crecimiento urbano. UPC

Schweitzer, M. (2020). La producción de un territorio desigual en Argentina. Concentración, primacía y macrocefalia. Redes, 25(3), 1051-1070. http://dx.doi.org/10.17058/redes.v25i3.14968

Tauber, F. (1994). Chascomús. Pautas para una estrategia de desarrollo. Municipalidad de Chascomús y Fundación Foro. http://sedici.unlp.edu.ar/handle/10915/86330

Vitalone, C (2013). Cuadrículas en la organización de territorio bonaerense del siglo XIX. Instituto Cultural de la Provincia de Buenos Aires. https://libros.unlp.edu.ar/index.php/unlp/catalog/book/396 